\title{
Collective Sense-Making in Times of Crisis: Connecting Terror Management Theory with Twitter Reactions to the Berlin Terrorist Attack
}

[Published in Computers in Human Behavior: https://doi.org/10.1016/i.chb.2019.05.012]

Diana Fischer-Preßler ${ }^{1}$, University of Bamberg, Department of Information Systems and Social Networks Carsten Schwemmer, University of Bamberg, Chair of Political Sociology

Kai Fischbach, University of Bamberg, Department of Information Systems and Social Networks

\begin{abstract}
Recent terrorist attacks have increased the need to examine the public's response to such threats. This study focuses on the content of Twitter messages related to the 2016 terrorist attack on the Berlin Christmas market. We complement the collective sense-making perspective with the terror management theory (TMT) perspective to understand why people used Twitter in the aftermath of the attack. We use structural topic modeling to analyze our dataset of 51,000 tweets. Our results indicate that people used Twitter to make sense of the events and as part of typical reactions in TMT, that is, to validate their own worldviews and maintain their self-esteem. In accordance with TMT, we found that people used Twitter to search for meaning and value, show sympathy for victims and their families, or call for tolerance, but also to express nationalistic sentiment and greater hostility toward values and views other than their own. We further show that topics varied over the course of the attack and in the days that followed. Whereas in the first two days there were many emotion-related tweets and operational updates, subsequent days saw more opinionrelated tweets. Our findings contribute to the literature on collective behavior in the aftermath of terrorist attacks.
\end{abstract}

\section{Keywords}

Terrorist attacks, social media, Twitter, topic modeling, terror management theory, collective sensemaking.

\footnotetext{
${ }^{1}$ Corresponding author. E-Mail address: diana.fischer-pressler@uni-bamberg.de
} 


\section{Introduction}

Terrorism is a constant, looming threat and issue of great concern affecting nations and people worldwide (Rogers, Amlôt, Rubin, Wessely, \& Krieger, 2007). Modern terrorism, which is often motivated by religious beliefs, seeks to incur high numbers of casualties and aims for global transformation. Terrorists are frequently willing to commit suicide in carrying out their acts and use weapons of mass destruction. The organization of terrorism is often decentralized and diffuse, with its purveyors united by common goals and/or experiences rather than through direct personal interaction (Crenshaw, 2000). The internet makes it particularly easy for terrorists to acquire critical information, such as tutorials on bomb-making, which increases the threat of lone actors (Cohen, Johansson, Kaati, \& Mork, 2013). The general belief is that terrorist attacks will continue, which increases the fear of becoming a victim (Kruglanski et al., 2013) and creates a heightened sense of uncertainty and anxiety (Bux \& Coyne, 2009).

There is evidence that individuals increasingly use social networking sites (SNS) such as Facebook and Twitter in the aftermath of terrorist attacks to make sense of the events. Sense-making as used here is the process through which individuals try to understand, through interaction with others, events that are new, uncertain, confusing, or violent (Heverin \& Zach, 2012; Maitlis \& Christianson, 2014). In times of terrorist attacks, the sense-making process has been found to be highly emotional at both the individual and collective level. In such catastrophic situations, individuals want to share with others the intense emotions regarding the event that can arise. This sometimes happens among so many people that the collective adopts a similar emotional state (Cornelissen, Mantere, \& Vaara, 2014). For instance, Kiwan (2016) showed that shortly after the Charlie Hebdo attacks in Paris in January 2015, the hashtag \#JeSuisCharlie ("I am Charlie") spread across Twitter and Facebook as people expressed solidarity with the victims. It was the most frequently used hashtag on Twitter in the hours after the attacks (Kiwan, 2016).

While there is research on SNS usage for collective sense-making in the context of crisis events (e.g. Heverin \& Zach, 2012; Kaewkitipong, Chen, \& Ractham, 2016; Stieglitz, Bunker, Mirbabaie, \& Ehnis, 2018), there is still a need to investigate the psychological underpinnings of the use of SNS for collective sensemaking in crisis situations (Neubaum, Rösner, Rosenthal-von der Pütten, \& Krämer, 2014; Stieglitz et al., 2018). In addition, while research on sense-making regards emotions as an important part of the sensemaking process (Maitlis \& Christianson, 2014), it lacks an explanation of how people cope, through certain behaviors, with the negative emotions caused by a terrorist attack. Terror management theory (TMT, Greenberg, Pyszczynski, \& Salomon, 1986) provides a valuable and widely used explanation of human reactions in the terrorism context (e.g., Das, Bushman, Bezemer, Kerkhof, \& Vermeulen, 2009; Dunkel, 2002; Landau et al., 2004). According to TMT, when terrorist attacks remind them of their vulnerability and mortality, people employ psychological defenses aimed at reducing anxiety and enhancing their selfesteem by posing their worldviews (e.g., liberal values and lifestyle) against other worldviews (e.g., religiously motivated terrorism; Dunkel, 2002; Hayes et al. 2010; Pyszczynski, Solomon, \& Greenberg, 2003). They accomplish this largely through interactions with others: agreement and approval from other 
people with the same cultural worldview (in-group) provide support for the "correctness" of one's worldview and help maintain self-esteem, whereas disagreement and disapproval reduce the psychological stability these provide. Several studies confirmed the hypotheses of TMT and have found that mortality salience causes, among others, out-group discrimination and is related to extreme or ostracizing behavior (for a review, see Burke, Martens, \& Faucher, 2010).

TMT complements the sense-making perspective by explaining the value of certain behaviors for coping with terrorist attacks and reducing people's anxiety. In particular, in the aftermath of terrorist attacks, people have been found to exhibit anxiety-reducing behavior and worldview defense, such as through praying, searching for meaning and value, and engaging in pro-social and altruistic behavior, but conversely also by exhibiting greater degrees of prejudice or stereotyping and showing less tolerance and greater hostility toward groups different from themselves (Pyszczynski, 2004; Yum \& Schenck-Hamlin, 2005). Hence, in the aftermath of terrorist attacks, people may use SNS to actuate this sense-making behavior, for example, as a venue for discussing their opinions related to an attack and receiving affirmation from others regarding their own worldviews (Fischer, Eismann, \& Fischbach, 2016).

Typically, TMT studies use an experimental design and observe human behavior at the individual level (Burke et al., 2010). Although there is a rich body of such individual TMT research, we have fewer data and less understanding about the reaction to terrorism at the collective level. The purpose of this article is, therefore, to investigate these reactions in the aftermath of a terrorist attack at the collective level.

We conducted a case study by analyzing Twitter content related to the terrorist attacks on a Christmas market in Berlin, Germany, on 19 December 2016. This attack took place during a time in which the atmosphere in Europe was already tense due to a high number of religiously motivated terrorist attacksin comparison to previous years_-for which ISIS (Islamic State) claimed responsibility (Haugerud, 2016). Those attacks also led to hostile reactions against refugees, and fears were expressed that refugees were potential terrorists, although many of these same refugees had actually escaped the terror caused by ISIS in the Middle Eastern countries from which they came. The so-called "refugee crisis" caused by the conflicts in the Middle East were leading large numbers of refugees from the conflict regions to flee to Europe, and so immigration was already a central topic in the political and social debates of that period in Germany and across the continent (Holmes \& Castaneda, 2016). Political and public debate in Germany was polarized, with positions ranging from Islamophobia to "Willkommenskultur" (culture of welcome) being expressed (Holmes \& Castaneda, 2016). Against this contextual background and the research gaps we have identified, our study addresses the following research question:

- RQ1: What terror management reactions occurred in the collective response of German-speaking Twitter users in the aftermath of the Berlin terrorist attack?

In addition, prior studies on SNS and crisis situations have shown that different reactions and needs are prevalent during the course of such events. Studies in this context focus, for example, on natural crisis such as hurricanes, fires, or floods, and examine different issues arising before, during, and after the crisis event 
itself (e.g., Kaewkitipong et al., 2016; Takahashi, Tandoc, \& Carmichael, 2015; Vieweg, Hughes, Starbird, \& Palen, 2010). Another research strand investigates the escalation of online-hate after terrorist attacks, with a focus on specific online hate-related discussions that arise after such attacks (Kaakinen, Oksanen, \& Räsänen, 2018). A crucial related question is whether some crisis-related topics such as online-hate are affected by temporal patterns in the aftermath of a terrorist attack. Thus, to understand the scope and emergence of topics in the aftermath of a terrorist attack, there is a need for research about the dynamics of online discussions, which leads to our second research question:

- RQ2: To what extent do temporal patterns affect Twitter users' reactions in the aftermath of the terrorist attack?

In the following sections, we first discuss the importance of sense-making during terrorist attacks as well as the role of SNS and Twitter in particular for sense-making at the collective level in crisis events. We then review research on TMT and explain our analytical framework derived from TMT research, which serves as our theoretical lens for this case study. Next, we present our data collection, that is, the collection of all tweets containing crisis-specific hashtags in the seven days after the terrorist attack. We introduce our methodology in the subsequent section. Since we analyze the variety of responses at the collective level, as well as the dynamic of these responses, we use structural topic modeling as a method for automated content analysis of our Twitter corpus. Subsequent sections provide the results of our analysis and the discussion. Finally, we outline policy implications, limitations, future research directions, and our conclusions.

\section{Theoretical and conceptual background}

\subsection{Sense-making during terrorist attacks}

Terrorist attacks are intentional, random, and catastrophic by design, and thus create high levels of uncertainty and feelings of fear, vulnerability, and distress. The ultimate aim of terrorism is psychological (Bux \& Coyne, 2009). The randomness of when and where a terrorist attack might take place often creates an ongoing threat. Anyone in the "wrong place at the wrong time" can become a victim, which causes people to feel threatened both personally and collectively. Beyond the injuries and deaths these attacks cause, they also have the potential to destabilize governments, economic development, and civil harmony (Baez et al., 2017). Thus, by affecting many individuals beyond those who suffer direct physical harm, these attacks constitute a social threat (Lerner, Gonzalez, Small, \& Fischhoff, 2003).

During low-probability, high-impact, uncertain, and ambiguous situations such as terrorist attacks, people are very likely to seek clarification regarding what is happening and thus try to make sense of the events (Weick, 1988). In particular, people search for and interpret information from their environment to fill the cognitive gaps caused by the uncertain situation (Maitlis \& Christianson, 2014; Weick, 1988). According to Maitlis and Christianson (2014, p. 67), sense-making is "a process, prompted by violated expectations, that involves attending to and bracketing cues in the environment, creating intersubjective meaning through 
cycles of interpretation and action, and thereby enacting a more ordered environment from which further cues can be drawn." Sense-making is both an individual and a social activity (Weick, 1995). Thus, it includes individual interpretation, but also occurs between people as meaning is discussed, challenged, and jointly constructed (Maitlis \& Christianson, 2014). Sense-making thus involves communication between individuals to find missing pieces of information and, particularly during uncertain crisis events, the process relies heavily on interactions with others (Heverin \& Zach, 2012).

\subsection{Social networking sites, Twitter and sense-making}

Due to their particular features, SNS are particularly helpful in facilitating sense-making during crisis events. Generally, SNS platforms allow users to construct unique profiles, access and create digital content, and protect that content from search mechanisms. They further enable users to connect with other users of the platform and view their own connections and those between others (Kane, Alavi, Labianca, \& Borgatti, 2014).

In this study, we focus on Twitter, an SNS that allows users to send and receive short texts with a maximum length of 140 characters at the date of data collection (it has since increased this length to 280 characters). Twitter also allows users to "follow" other users of interest, which generates notification of new followers, likes, or repostings of tweets (so-called retweets of a user's content). These connections do not require reciprocity; a user who is followed does not have to follow the follower (Huberman, Romero, \& Wu, 2009). In addition, content on Twitter is often categorized by annotating tweets with hashtags (e.g., "\#PrayForBerlin"), which are typically used to direct user attention to specific topics or facilitate following certain discussions (Oh, Chanyoung, \& Rao, 2012). The hashtag feature is a crucial mechanism for information diffusion on Twitter and other SNS platforms during crisis events. This feature also creates a public opinion space that promotes exchange of opinions on current (political) debates. It also makes it a primary platform for users to express publicly their opinions regarding events of national significance (Williams \& Burnap, 2016).

While SNS are not the sole means by which communication about and making sense of crisis events is enabled, the role of SNS in crisis events has been increasing (Simon, Goldberg, \& Adini, 2015; Sutton et al., 2014). Because SNS enable users to interact, collaborate, and upload user-generated content in real time from devices with internet access such as smartphones, the platforms can be of tremendous use during highly dynamic crisis situations (Mendoza, Poblete, \& Castillo, 2010). In addition, these real-time, two-way communication and many-to-many information broadcasting tools allow active public participation during crisis events by making it possible to browse others' published information, post, and leave public comments (e.g., Palen, Vieweg, Liu, \& Hughes, 2009; Pang \& Ng, 2016). Thus, even people who are not at the crisis scene can make sense of events by accessing information posted in SNS.

Prior research investigated Twitter communication during different human-made crisis events from the sense-making perspective. Oh et al. (2012; 2015), for instance, found that communication via Twitter during the so-called "January 25 Revolution" in Egypt in 2011 was structured around and quickly became 
dominated by a small number of hashtags and concluded that the use of hashtags contributed significantly to collective sense-making. Stieglitz et al. (2018) examined the Twitter data regarding the deliberate crash of Germanwings Flight 9525 in March 2015 in the French Alps, the terrorist bombings in Brussels in March 2016, and the Lindt Café siege in Sydney, Australia, in December 2014. They argued that, in particular, people who were not directly affected by the crises used Twitter for sense-making by sharing information and their feelings regarding the events. In addition, Heverin and Zach (2012) investigated people's Twitter usage for collective sense-making during three shootings on U.S. college campuses. The authors found that by following specific hashtags, people not only saw specific information posted by others but also the feelings, perspectives, and views of others. The authors conclude that Twitter served as a communication channel that connected the individual to the collective and helped Twitter users make sense of the events. Additionally, Eriksson (2015) showed that people used Twitter for coping and meaning-making at the collective level after the 2011 terrorist attack in Norway. However, a detailed analysis of the variety of topics occurring in the aftermath of terrorist attacks is still missing.

Moreover, prior research indicates that the content of topics varies during the course of crisis events (e.g., EENA, 2016; Jong \& Dückers, 2016; Takahashi et al., 2015; Vieweg et al., 2010). For instance, a study by Olteanu, Vieweg, and Castillo (2015) analyzed similarities between several natural and human-made crisis events such as earthquakes or suicide bombings and found that topics during what they called instantaneous crises (those for which there is no warning) in the first 12-24 hours on SNS include situationrelated tweets such as advice and caution as well as emotion-related tweets such as sympathy and support for the affected people. This is followed by information about infrastructure and the situation of affected people.

In addition to these similarities in the appearance of topics on a more general level-such as opinion-, emotion-, and situation-related tweets between various crisis events-there are also differences in topic content and degree. Notably, findings in research on natural crisis events such as floods indicate that people affected also use SNS for information exchange to coordinate self-organization and/or relief efforts with aid organizations as part of recovery activities in the aftermath of the crisis (e.g., Kaewkitipong et al., 2016; Takahashi et al., 2015), whereas in the aftermath of human-made crises SNS are instead used to make sense of and cope with the events (e.g., Eriksson, 2015; Heverin \& Zach, 2012). Regarding the latter one, Nilsen, Hafstad, Staksrud, and Dyb (2018), investigated the use of different SNS by survivors in the aftermath of the terrorist attack at Utøya, Norway in 2011. Generally, survivors attributed their SNS use to five different reasons: information exchange; giving and receiving social support; mourning; performing different symbolic actions such as changing the profile pictures to the Norwegian flag; and participating in discussions about the attack. Immediately after the attack SNS were particularly helpful for information exchange about the own and others camp participants health and situation to learn who survived the attack indicating that also in the aftermath of terrorist attacks different topics on Twitter are prevalent. 


\subsection{Terror management theory}

We use TMT to complement the sense-making perspective by explaining why people who perceive an existential threat take certain social actions and uphold a particular set of values and beliefs to reestablish their own sense. According to Pyszczynski et al. (2003), terrorist attacks are "natural" death reminders and can be seen further as attacks against one's cultural worldview (e.g., basic Western beliefs and values such as democracy). People who have been threatened existentially by reminders of mortality (i.e., who are under conditions of what is called mortality salience) try to buffer their death anxiety by maintaining their self-esteem, holding up their cultural worldviews, and defending their own "in" group (Greenberg et al., 1986). The cultural worldview is a human-constructed belief regarding the nature of reality shared by individuals in a group that helps manage the fear of death by providing a meaningful explanation of life and a comforting conception of the world. The cultural worldview also provides standards for good or bad behavior - a way of life, as in a cultural, religious, or political system-that directs people's behavior to acquire self-esteem. People's self-esteem is their feeling that they are significant and important contributors to their worldview; it helps people attain a literal or symbolic sense of immortality (Greenberg et al., 1986).

Self-esteem and cultural worldviews are maintained by social consensus and by influencing others in accordance with our own worldviews (Pyszczynski et al., 2003). When thoughts of death are brought into focus, people immediately try to remove them by, for example, denying their vulnerability to death (Greenberg, Arndt, Pyszczynski, \& Solomon, 2000). The problem of death, however, resides beneath consciousness, and so typically after a brief distraction from the death-related thought the so-called distal defenses_that is, the maintenance of worldviews and self-esteem (Pyszczynski, Greenberg, \& Solomon, 1999) - are triggered. The distal defenses are outside the awareness of consciousness and therefore not particularly obvious to individuals as they employ the defensive behavior (Burke et al., 2010).

In summary, reminders of death make people aware of their own mortality, which in turn triggers their need to protect their beliefs through certain defense strategies. In particular, TMT suggests that terrorist attacks function as triggers, which influences the SNS user's online reactions to cope with such events. By providing an explanation for why it is so important for people to reestablish self-esteem and cultural worldview after death reminders, TMT illuminates various human behaviors and attitudes (Burke et al., 2010). Table 1 is an overview of the six common distal terror-management reactions ${ }^{2}$ and corresponding examples at the individual level, based on Pyszczynski et al. (2003) and identified by Yum and Schenk-Hamlin (2005) after the $9 / 11$ attacks in the United States. We use these reactions as theoretical lens to interpret our findings from a TMT perspective.

2 Two further reactions, according to (Yum \& Schenck-Hamlin, 2005), would be increased personal communication and no action. We, however, excluded the no action category because we analyze data only from active Twitter users and thus had no data regarding users who did not respond to the attack, and we excluded the increased personal communication category because we had no access to personal Twitter messages. 


\begin{tabular}{|l|l|l|}
\hline No. & Distal reaction & Examples \\
\hline 1 & Search for meaning and value & Prayer, attending religious services, candlelight vigils \\
\hline 2 & $\begin{array}{l}\text { Nationalistic sentiment, less } \\
\text { tolerance, and greater hostility } \\
\text { toward different values and views }\end{array}$ & $\begin{array}{l}\text { Prejudice, stereotyping, listening to traditional patriotic } \\
\text { songs, disparaging different cultural values }\end{array}$ \\
\hline 3 & Counter-bigotry activism & Calling for tolerance and understanding \\
\hline 4 & Altruistic or pro-social behaviors & Empathy, comforting, donating, volunteering \\
\hline 5 & Gratitude for helpers & $\begin{array}{l}\text { Respect for first responders who helped in the } \\
\text { aftermath of an attack }\end{array}$ \\
\hline 6 & Information seeking and sharing & $\begin{array}{l}\text { Seeking relevant information by watching TV and } \\
\text { talking to people }\end{array}$ \\
\hline
\end{tabular}

Table 1. Classification scheme adapted from Yum and Schenk-Hamlin (2005)

In the next section, we explain those reactions and how they may appear in SNS by relating them to recent findings on SNS utilization during crises events.

\subsection{Terror management reactions and social networking sites}

The first reaction "search for meaning and value" includes actions related to grieving and questing for meaning such as attending a candlelight vigil or memorial ceremony, as well as shock and disbelief. In the aftermath of a traumatic event such as a terrorist attacks, simple shock and disbelief as well as the need to pray and come together are among the initial responses to confirm one's values (Eriksson, 2015; Yum \& Schenck-Hamlin, 2005). Although it is not possible to light a candle on SNS platforms, they enable users to express similar symbolic reactions and solidarity_for instance, with statements (e.g., \#JeSuisCharlie) or pictures-and share them with others.

The second reaction "nationalistic sentiment, less tolerance, and greater hostility toward different values and views" refers to hostile reactions against perceived outgroups or prejudice. Mortality salience increases positive feelings about others who share similar religious and political beliefs and negative feelings towards those who differ in these aspects (Cohen, Ogilvie, Solomon, Greenberg, \& Pyszczynski, 2005), motivates aggression against others who may threaten one's worldview (McGregor et al., 1998), and increases people's stereotypical thinking (Schimel et al., 1999). Also, research on online hate indicates that SNS are used after terrorist attacks to disseminate racist comments and ideological views (Kaakinen et al., 2018; Williams \& Burnap, 2016). In particular, terrorist attacks function as a trigger for this so-called online hate, for instance, towards groups with characteristics similar to those of the terrorist perpetrator (Williams \& Burnap, 2016). SNS enable users to find likeminded others (such as through the hashtag feature) without special restrictions and then share the same thoughts. Such affordances make users more willing to publish extreme thoughts that might be rejected in other contexts (Kaakinen et al., 2018; Williams \& Burnap, 2016).

The third reaction comprises responses that are related to counter-bigotry activism such as showing understanding or calling for tolerance and is the opposite of the second reaction. It includes topics against 
hate, ostracism, and nationalism and is in line with previous research that found a variety of reactions and diverse online discourse after such events (Yum \& Schenck-Hamlin, 2005), as well as research that found mortality salience influences people's political preferences (e.g., Landau et al., 2004; Weise et al., 2007).

The fourth reaction refers to altruistic or pro-social behaviors including, for instance, showing empathy, donating, or sharing emotions with others via SNS after crisis events. In the aftermath of a human-made crisis such as a terrorist attack there is an increase in such behavior on SNS to validate feelings, offer comfort, and show empathy with victims and their families by publishing personal information (e.g., Neubaum et al., 2014; Stieglitz et al., 2018). Research shows further that mortality salience leads to prosocial behavior as a source of self-esteem, such as by donating and volunteering (Jonas, Schimel, Greenberg, \& Pyszczynski, 2016; Zaleskiewicz, Gasiorowska, \& Kesebir, 2015).

The fifth reaction "gratitude for helpers" comprises responses that acknowledge the efforts and help of socalled "first responders" (e.g., rescue workers, police, et al.) during crisis events. This reaction was found, for instance, during the 9/11 attack, in which people showed respect for all the rescue workers and fireman (Pyszczynski et al., 2003) and in the aftermath of the Norway attack as people showed gratitude for friends and family who supported them during the difficult times after the attack via SNS (Nilsen et al., 2018).

Finally, the sixth reaction "information seeking and sharing" via SNS is also observed in crisis events. As explained in the prior section, SNS provide specific affordances such as finding likeminded others or immediate information exchange between users. During crisis events, SNS thus helps fulfill general and personal information needs for making sense of the events by helping people understand, for instance, what exactly happened in the crisis and what happens next, or for verifying the wellbeing of loved ones (e.g., Eriksson, 2015; Heverin \& Zach, 2012; Neubaum et al., 2014).

\section{Case description for the Berlin terrorist attack}

On 19 December 2016, a truck was hijacked and then intentionally driven into a crowded Christmas market at Breitscheidplatz in Berlin, Germany. Twelve people were killed and more than 50 people were injured before the truck was finally stopped. The truck driver who had been hijacked was one of the victims; he was found murdered in the cab. Soon after the attack, the police stated that the actual perpetrator was still on the loose, possibly armed and dangerous. On 21 December, an asylum seeker who had failed in an effort to gain asylum in Germany and was said to have pledged allegiance to the Islamic State terrorist group was declared publicly as the chief suspect. He was finally found in Italy on 23 December (dpa, 2017).

Public authorities used Twitter to inform the public about the investigation from the time of the attack at the market and over the following days. 


\section{Method}

\subsection{Data collection and descriptive statistics}

When it comes to analyzing the use of SNS, most scholars focus either on Twitter or Facebook, as these platforms have the largest user bases in many countries. In general, Twitter is not used as widely as Facebook in Germany. According to the results of Frees and Koch (2018), 33\% of Germans age 14 and older used Facebook at least once a week in 2017, compared to $3 \%$ from the same age group that use Twitter. While this is a substantial gap, it is getting smaller: the figures for 2018 are $31 \%$ and $4 \%$ for Facebook and Twitter, respectively. Nevertheless, Twitter is a crucial platform for communicating with others during a crisis event (see, e.g., Kaufhold \& Reuter, 2016 for Germany; Stieglitz et al., 2018 for multiple countries). It would have been desirable to analyze and compare both platforms in this article; unfortunately, at the time of data collection, Facebook only allowed the retrieval of content from public pages, which is why we chose the Twitter platform for our data collection. As we show in the remainder of our work, many private users, but also public authorities, used the platform to exchange information in the aftermath of the Berlin Christmas market terrorist attack.

In December 2016, we connected to Twitter's Application Programming Interface (API) to acquire tweets related to the Berlin attack. The API offers several endpoints to extract tweets, most notably the "Search API," which can be utilized to retrieve tweets published in the past seven days, and the "Streaming API," which generally allows for retrieving at most a $1 \%$ sample of all tweets for a given query (Morstatter, Pfeffer, Liu, \& Carley, 2013) in real time. To avoid any rate limits, we collected our data with the Search API and collected all tweets that included the following hashtags (translated, with the original German in parentheses) used during the week of the Berlin Christmas market attack: \#berlinassassination (\#berlinattentat), \#breitscheidplatz, \#berlinattack (\#anschlagberlin), \#berlinattacks, \#christmasmarketattack, \#prayforberlin, \#prayforgermany, \#lamaberliner (\#ichbineinberliner), \#weareberlin (\#wirsindberlin), and \#bestrongforberlin. More specifically, we constructed a query for retrieving all tweets created between 19 and 25 December 2016 that included at least one of these hashtags. In total, we collected 656,291 tweets posted by 327,903 users, of which 481,140 were retweets.

We removed all retweets, as information diffusion patterns are not relevant for our paper. In addition, we retained in our sample only tweets for which Twitter classified the language as German, for two reasons. First, our empirical approach requires proper interpretation of a statistical model fitted on large quantities of textual data, for which mixing texts of different languages is problematic. Second, because the terrorist attack happened in a German city, we assumed that Germans-and thus German speakers-were most likely exposed by media or locally in Berlin to the attack. This approach is not without limitations: for example, Germans could have tweeted in other languages. However, other approaches such as filtering data by geolocations are not appropriate alternatives, because only a very small share of tweets includes information about user location. While our approach may underestimate the total number of tweets that 
referred to the terrorist attack, it enabled us to create a robust data set of relevant tweets. After applying the filtering procedures, our final dataset includes 51,256 tweets posted by 22,439 users. ${ }^{3}$

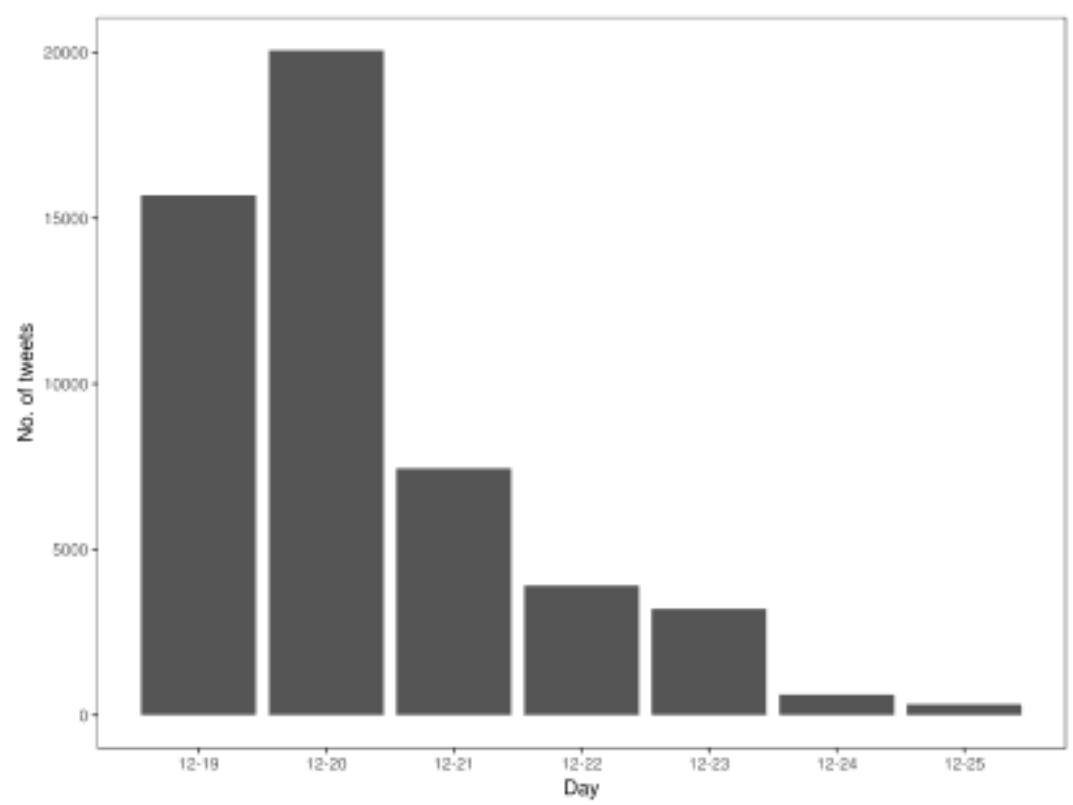

Figure 1. Distribution of tweets in our final dataset in German language in the December week of the

$$
\text { Berlin attack }(n=51,256) \text {. }
$$

Figure 1 shows the number of tweets in our final dataset on the day of the attack and on subsequent days. Our sample includes tweets posted immediately after the attack took place (around 8:00 p.m.). Most of the Twitter content related to the terrorist attack was posted during the first two days. In contrast, only about $15 \%$ of all tweets were posted between December 21 and December 25. This is not surprising given that both the desire for information as well as uncertainty are high shortly after a terrorist attack—when lives are at stake-and people will urgently seek to clarify the situation to ease their own anxiety and uncertainty (Lachlan, Spence, \& Seeger, 2009).

\subsection{Topic modeling}

Ideally, human coders would examine and manually annotate each tweet of the dataset to gain detailed insights into SNS usage related to terrorist attacks (RQ1). As this is hardly feasible for a dataset comprising more than 50,000 observations, we instead relied on topic modeling as a method for automated content analysis. Topic modeling is a clustering method for analyzing large amounts of textual data. Topic models allow for discovering latent topics from text documents automatically (Blei, 2012). A topic is a set of words representing interpretable themes within documents, which in our dataset are tweets. Documents, in turn, are represented as a mixture of these topics. Therefore, after fitting a topic model, a tweet contains proportions of several topics. Generally speaking, a tweet might be ascribed mainly to one certain topic (e.g., with a proportion of $60 \%$ ) and to other topics with a smaller proportion (e.g., a proportion of $30 \%$ to a

${ }^{3}$ We used the R packages by Benoit et al. (2018), Pedersen (2018) and Wickham (2017). 
second topic and $10 \%$ among remaining topics). As tweets at the time of the terrorist attack were limited to 140 characters, their content often refers to one specific topic. To illustrate this with our data: $80 \%$ of topic proportions of the tweet "Our wholehearted sympathy for all victims and their families" posted on 20 December relate to a single topic, which we labeled as "sympathy and prayers." The remaining $20 \%$ are distributed across several other topics. Moreover, each topic is modeled as a probability distribution over words, which indicates the most important words of a topic. For instance, among the most important words of the topic "search for meaning and sense" are "happened," "why," and "dead."

To prepare for topic modeling, all tweets were processed into a corpus with common methods of text analysis (Grimmer \& Stewart, 2013): Tweets were treated as bags of words in which each term represents a feature and word order is disregarded. In addition, terms without semantic meaning, such as German equivalents for the stop words "the" or "a," were removed from the corpus. Furthermore, we applied snowball stemming to all words (i.e., reducing inflected words to their word stem), which means that terms such as "family" and "families" reduce to the word stem "famili."

As our data include not only tweets on the day of the terrorist attack but also on the following days, we expected that content related to the Berlin attack would differ over time. For that reason, we utilized a special variant of a topic model called a structural topic model (Roberts et al., 2014). In addition to representing documents as distributions over topics, structural topic models allow the inclusion of document-specific covariates that influence topic proportions for each document. Drawing on this feature, we incorporated a dummy variable in our model indicating whether a tweet was posted during the day of and the day after the terrorist attack, or in the five days that followed. This allowed us to unfold temporal patterns in collective behavior on Twitter in relation to the terrorist attack (RQ2).

Although topic modeling is very useful for categorizing large text corpora, it is limited by the need to determine the number of topics manually. To fit a model that best represents the data given our attempt to gain insights about Twitter usage during and in the aftermath of terrorist attacks, we fitted four different models with 10, 20, 30, and 40 topics. Choosing too many topics for the algorithm results in many topics that are only minimally distinct, whereas choosing too few topics results in a mixture of topics that are too broad. We chose 10 topics as the smallest model that would allow for a connection of our empirical data with the six distal terror management reactions. In addition, we chose 40 topics as the largest model because tweets were at the time restricted to 140 characters. Moreover, tweets were collected for a single event via hashtag filtering, and our corpus of about 50,000 tweets is only of moderate size. Hence, textual variability is substantially reduced in our sample and, therefore, larger models are not useful for investigating our sample.

After fitting all models, we calculated the semantic coherence and exclusivity of the statistical measures to determine the best model. Semantic coherence is higher if more probable words in a topic frequently cooccur (Mimno, Wallach, Talley, Leenders, \& McCallum, 2011), whereas exclusivity achieves higher values if more words are exclusive to corresponding topics (Lucas et al., 2015). The figure in Appendix A illustrates 
the average and median values for both measures, computed for all four models. In terms of desirable statistical properties, the figure shows that smaller models with 10 and 20 topics outperform the larger models with 30 and 40 topics, as they both achieve better values for semantic coherence and exclusivity.

\subsection{Qualitative validation}

Beyond statistical diagnostics, validation by humans is the most important way to evaluate topic models (Chang, Boyd-Graber, Gerrish, Wang, \& Blei, 2009; Wallach, Salakhutdinov, \& Mimmo, 2009). Using an application for qualitative validation of structural topic models (R Core Team 2018; Schwemmer 2018), we implemented the suggestions by Debortoli, Müller, Junglas, and Vom Brocke (2016) to validate our models: two of the present paper's authors independently investigated the models with 10 and 20 topics by analyzing the most likely words and tweets with the highest proportions for a given topic to determine whether the structure made sense. In doing so, we inspected the 50 most-likely terms of a topic as well as the 50 documents with the highest proportions for a topic. We assigned corresponding labels in accord with the highest proportions of words and highly representative documents for each topic. We chose the model with 20 topics as our final model, because it was the best and most intuitive model for our research task and the topics were neither too broad nor too narrow. Disregarding some minor wording differences, we reached an inter-coder reliability of 0.9 for this model. The coders discussed and resolved remaining discrepancies in consensus. Finally, two of the present paper's authors independently mapped the 20 topics of our final model to the typical TMT reactions indicated in table 1.

To illustrate the coding procedure and results of the qualitative validation of our topic model, we show this on one of our 20 topics. For this illustration we used topic 4 , which accounts for about $4.8 \%$ of all the words of our dataset and is labeled "Togetherness" (a label we assigned after examining both the word distribution and the most likely tweets associated with the topic). The topic comprises highly likely words such as "together," "city," or "nation." Tweets associated with this topic are mainly about mourning together, showing empathy, and showing common signs (e.g., lighting candles, or illuminating buildings in particular colors) and support for the victims of the attacks. In particular, the topic contains phrases such as "The Brandenburg Gate in \#Berlin will be illuminated tonight in black-red-gold" or "Berlin is mourning together at the Brandenburg Gate."

\section{Results}

\subsection{Twitter content}

To answer our first research question and thus to make sense of the topics on Twitter in the aftermath of the 2016 Christmas market terrorist attack in Berlin from a TMT perspective, we classified the topics (Table

2) according to common distal terror management reactions. "Distal reactions" are the topic categories based on the typical TMT reactions after terrorist attacks, as explained above in the TMT section. Note that we translated the words and example reactions from German into English. 


\begin{tabular}{|c|c|c|c|c|}
\hline Distal reaction & Label & $\begin{array}{l}\text { Topic } \\
\text { pro- } \\
\text { portion }\end{array}$ & Most probable terms & $\begin{array}{l}\text { Example reactions on } \\
\text { Twitter }^{4}\end{array}$ \\
\hline \multirow[t]{2}{*}{$\begin{array}{l}\text { (1) Search for } \\
\text { meaning and } \\
\text { value }\end{array}$} & Togetherness & $4.8 \%$ & $\begin{array}{l}\text { christmasmarket, good, } \\
\text { grief, day, evening, strong, } \\
\text { together, city, nation, stay, } \\
\text { heart, Brandenburg, net, } \\
\text { sign, mayor, gate, reacts }\end{array}$ & $\begin{array}{l}\text { The Brandenburg Gate in } \\
\text { \#Berlin will be illuminated } \\
\text { tonight in black-red-gold; } \\
\text { Memorial concert \#Berlin- } \\
\text { United at Brandenburg } \\
\text { Gate. }\end{array}$ \\
\hline & $\begin{array}{l}\text { Search for } \\
\text { meaning and } \\
\text { sense }\end{array}$ & $4.6 \%$ & $\begin{array}{l}\text { sad, happened, dead, time, } \\
\text { christmas, hope, good, go, } \\
\text { real, ill, never, why, short, } \\
\text { fast, Islam, friend, wishes, } \\
\text { hear, thinking, all, find, } \\
\text { speechless, unbelievable }\end{array}$ & $\begin{array}{l}\text { So endlessly sad. In what } \\
\text { are supposed to be happy } \\
\text { times, we have to go to } \\
\text { funerals. And all this just } \\
\text { before Christmas. I can't } \\
\text { believe it. So } \\
\text { unnecessary. So } \\
\text { pointless. Sad. }\end{array}$ \\
\hline \multirow[t]{3}{*}{$\begin{array}{l}\text { (2) Nationalistic } \\
\text { sentiment, less } \\
\text { tolerance, and } \\
\text { hostility toward } \\
\text { different values } \\
\text { and views }\end{array}$} & Xenophobia & $5.2 \%$ & $\begin{array}{l}\text { primal, right, terrorists, } \\
\text { better, @world, security, } \\
\text { @picture, come, give, } \\
\text { should, border, nothing, } \\
\text { somebody, wrong, need, } \\
\text { open, citizen, protect }\end{array}$ & $\begin{array}{l}\text { If the state can't protect its } \\
\text { citizens, they must protect } \\
\text { themselves. Is it possible } \\
\text { that all these idiots have } \\
\text { multiple identities in order } \\
\text { to get money from the } \\
\text { state again and again? }\end{array}$ \\
\hline & $\begin{array}{l}\text { Political } \\
\text { accusation / } \\
\text { Less tolerance }\end{array}$ & $3.7 \%$ & $\begin{array}{l}\text { say, \#cdu, right, \#lslam, } \\
\text { \#spd, \#police, \#refugee, } \\
\text { stay, \#IS, \#lorry, photo, } \\
\text { suspect, fixed, hopefully, } \\
\text { \#isi, \#Grüne, search, new, } \\
\text { suspect }\end{array}$ & $\begin{array}{l}\text { \#Grüne and \#spd block } \\
\text { strict laws to expel criminal } \\
\text { immigrants. All } \\
\text { \#RefugeeHelpers } \\
\text { \#LyingJournalists } \\
\text { \#Politicians from \#spd } \\
\text { \#cdu \#Grüne \#Linke are } \\
\text { also guilty of murder! }\end{array}$ \\
\hline & $\begin{array}{l}\text { Call for political } \\
\text { change }\end{array}$ & $6.6 \%$ & $\begin{array}{l}\text { \#merkel, life, politics, } \\
\text { country, blame, woman, } \\
\text { finally, rather, when, } \\
\text { \#seehofer, back, need, } \\
\text { government, \#csu, } \\
\text { statement }\end{array}$ & $\begin{array}{l}\text { Mrs. Merkel, when are you } \\
\text { retiring?; } \\
\text { @GovernmentSpokesman } \\
\text { when does \#Merkel admit } \\
\text { her mistakes in the } \\
\text { refugee crisis and resign? } \\
\text { If not now, when? }\end{array}$ \\
\hline \multirow[t]{2}{*}{$\begin{array}{l}\text { (3) Counter- } \\
\text { bigotry activism }\end{array}$} & $\begin{array}{l}\text { Call for } \\
\text { tolerance }\end{array}$ & $5.3 \%$ & $\begin{array}{l}\text { people, terror, hate, fear, } \\
\text { love, our, let, instead, } \\
\text { peace, information, new, } \\
\text { taunt, freedom, war, take, } \\
\text { anger, religion, need, } \\
\text { \#muslimsagainstterror }\end{array}$ & $\begin{array}{l}\text { The answer to the attacks } \\
\text { must be: more democracy } \\
\text { and openness. Otherwise } \\
\text { the terrorists do win; Kick } \\
\text { the terrorism ass with } \\
\text { open-mindedness. }\end{array}$ \\
\hline & $\begin{array}{l}\text { Against right- } \\
\text { wing } \\
\text { propaganda }\end{array}$ & $4.4 \%$ & $\begin{array}{l}\text { \#afd, since, say, really, } \\
\text { clearly, muslim, sadly, } \\
\text { question, days, ask, nazi, } \\
\text { pray, problem, nice, help, } \\
\text { no one, feeling, believing, } \\
\text { why, always }\end{array}$ & $\begin{array}{l}\text { It is so disgusting how } \\
\text { right-wing propaganda } \\
\text { uses this occasion. Really } \\
\text { disgusting } \\
\text { \#Breitscheidplatz; To all } \\
\text { Nazis who now say }\end{array}$ \\
\hline
\end{tabular}

${ }^{4}$ To ensure the anonymity of Twitter users, translations here are not verbatim. 


\begin{tabular}{|c|c|c|c|c|}
\hline & & & & $\begin{array}{l}\text { foreigners out: You make } \\
\text { my blood boil with shame! }\end{array}$ \\
\hline \multirow[t]{2}{*}{$\begin{array}{l}\text { (4) Altruistic or } \\
\text { pro-social } \\
\text { behaviors }\end{array}$} & $\begin{array}{l}\text { Sympathy and } \\
\text { prayers }\end{array}$ & $6.9 \%$ & $\begin{array}{l}\text { relatives, victims, thoughts, } \\
\text { our, incredibly, bereaved, } \\
\text { condolences, sympathy, } \\
\text { casualty, family, shocked, } \\
\text { prayer, strength, stunned }\end{array}$ & $\begin{array}{l}\text { Our wholehearted } \\
\text { sympathy for all victims } \\
\text { and their families; Sincere } \\
\text { sympathy and prayers for } \\
\text { the victims, their families } \\
\text { and relatives. }\end{array}$ \\
\hline & $\begin{array}{l}\text { Community } \\
\text { condolences }\end{array}$ & $4.6 \%$ & $\begin{array}{l}\text { \#berlin, mourns, opposition, } \\
\text { Iranian, tribute, pay, } \\
\text { \#attack, hear, ready, } \\
\text { important, message, } \\
\text { everywhere, heard, love }\end{array}$ & $\begin{array}{l}\text { \#Muenster is mourning } \\
\text { with \#Berlin; } \\
\text { @EUCommission mourns } \\
\text { with \#Berlin. Flags at half- } \\
\text { mast; Also Umbria mourns } \\
\text { with \#Berlin. }\end{array}$ \\
\hline $\begin{array}{l}\text { (5) Gratitude for } \\
\text { helpers } \\
\text { associated with } \\
\text { the attacks }\end{array}$ & $\begin{array}{l}\text { Gratitude for } \\
\text { helpers and } \\
\text { hashtag trends }\end{array}$ & $2.8 \%$ & $\begin{array}{l}\text { thanks, just, the, many, } \\
\text { released, news, latest, } \\
\text { newspaper, \#christmas, } \\
\text { operation, of, for, helper, } \\
\text { job, complete, attack, we, } \\
\text { \#security }\end{array}$ & Thanks to @TrafficPolice. \\
\hline \multirow[t]{5}{*}{$\begin{array}{l}\text { (6) Information } \\
\text { seeking and } \\
\text { sharing }\end{array}$} & $\begin{array}{l}\text { Operation } \\
\text { update } 1\end{array}$ & $7.2 \%$ & $\begin{array}{l}\text { \#berlin, lorry, \#attack, } \\
\text { \#terror, driver, @police } \\
\text { berlin, @policeberlin,, } \\
\text { video, stop, polish, shows, } \\
\text { facts, see, speed, co-driver, } \\
\text { Facebook, work, respect, } \\
\text { dead, incident }\end{array}$ & $\begin{array}{l}\text { The truck driver was } \\
\text { arrested and the co-driver } \\
\text { was found dead at the } \\
\text { accident location. }\end{array}$ \\
\hline & $\begin{array}{l}\text { Operation } \\
\text { update } 2\end{array}$ & $6.1 \%$ & $\begin{array}{l}\text { \#amri, ani, amri, \#anisamri, } \\
\text { assassin, shot, \#terror, } \\
\text { tunesi, wanted, \#germany, } \\
\text { found, public, \#mailand, } \\
\text { public, alleged, authority, } \\
\text { manhunt, police }\end{array}$ & $\begin{array}{l}\text { \#Police are searching for a } \\
\text { 24-year-old Tunisian Anis } \\
\text { Amri. }\end{array}$ \\
\hline & $\begin{array}{l}\text { Operation } \\
\text { update } 3\end{array}$ & $7.3 \%$ & $\begin{array}{l}\text { attack, police, knowledge, } \\
\text { crime, IS, accident, men, } \\
\text { terrorist attack, know, } \\
\text { suspect, arrested, talks, } \\
\text { thanks to, loud, known, so } \\
\text { far, of course, maiziére }\end{array}$ & $\begin{array}{l}\text { Update \#Breitscheidplatz } \\
\text { - De Maizière: Arrested } \\
\text { suspect denies crime. }\end{array}$ \\
\hline & $\begin{array}{l}\text { Operation } \\
\text { update } 4\end{array}$ & $5.1 \%$ & $\begin{array}{l}\text { suspect, refugee, sure, } \\
\text { stay, instantly, maybe, free, } \\
\text { true, caught, therefore, be, } \\
\text { find, link, Pakistan, wrong, } \\
\text { true, escape, armed }\end{array}$ & $\begin{array}{l}\text { Please do not call the } \\
\text { emergency number for tips } \\
\text { and questions. The official } \\
\text { number is ...; The real } \\
\text { perpetrator is still on the } \\
\text { loose. }\end{array}$ \\
\hline & $\begin{array}{l}\text { Operation } \\
\text { update } 5\end{array}$ & $3.5 \%$ & $\begin{array}{l}\text { world, dead, injured, } \\
\text { people, go, sad, hashtag, } \\
\text { lost, believe, difficult, oh, } \\
\text { multiple, whole, thereof, } \\
\text { @marcuspretzel }\end{array}$ & $\begin{array}{l}\text { We confirm } 9 \text { people } \\
\text { dead. Many police officers } \\
\text { are at \#Breitscheidplatz } \\
\text { investigating the } \\
\text { circumstances of the } \\
\text { crime. }\end{array}$ \\
\hline
\end{tabular}




\begin{tabular}{|c|c|c|c|}
\hline $\begin{array}{l}\text { Operation } \\
\text { update } 6\end{array}$ & $3.3 \%$ & $\begin{array}{l}\text { year, lorry-driver, } \\
\text { \#fakenews, attack, picture, } \\
\text { end, enough, confirmed, } \\
\text { hint, \#zdf, days, \#ard, last, } \\
\text { soon, event, @zdftoday }\end{array}$ & $\begin{array}{l}\text { Police Berlin: Please } \\
\text { upload your pictures and } \\
\text { videos at our portal. }\end{array}$ \\
\hline $\begin{array}{l}\text { Special } \\
\text { broadcast }\end{array}$ & $3.0 \%$ & $\begin{array}{l}\text { tomorrow, clock, afd, } \\
\text { political, live, disgusting, } \\
\text { night, rightwing, event, out, } \\
\text { use, good, silent } \\
\text { consequences, press } \\
\text { conference, topic, talk }\end{array}$ & $\begin{array}{l}\text { 13h live press conference } \\
\text { \#Breitscheidplatz; We } \\
\text { report in three special } \\
\text { broadcasts on the } \\
\text { incidents at } \\
\text { \#Breitscheidplatz. }\end{array}$ \\
\hline $\begin{array}{l}\text { Avoid } \\
\text { spreading } \\
\text { rumors }\end{array}$ & $5.7 \%$ & $\begin{array}{l}\text { media, rt, twitter, crap, stay, } \\
\text { tweet, little, show, place, } \\
\text { comment, important, } \\
\text { instantly, no, report, } \\
\text { speculation, reporting, } \\
\text { spread, god, @zdf, federal } \\
\text { government }\end{array}$ & $\begin{array}{l}\text { Stay calm. No speculation, } \\
\text { rumors, and panic } \\
\text { mongering on my timeline! } \\
\text { Please wait for the facts! }\end{array}$ \\
\hline $\begin{array}{l}\text { Criticism on } \\
\text { SNS reactions }\end{array}$ & $4.1 \%$ & $\begin{array}{l}\text { berlin, via, Germans, hours, } \\
\text { attack, authority, } \\
\text { @spiegelonline, Europe, } \\
\text { solidarity, forget, internet, } \\
\text { reaction, fail, @youtube, } \\
\text { France, \#terrorist, news, } \\
\text { warns }\end{array}$ & $\begin{array}{l}\text { \#BerlinAttack; } 24 \text { hours on } \\
\text { German Internet: } \\
\text { Cowardly knee-jerk } \\
\text { reactions. }\end{array}$ \\
\hline $\begin{array}{l}\text { Terror } \\
\text { information / } \\
\text { hashtag trends }\end{array}$ & $5.8 \%$ & $\begin{array}{l}\text { Germany, \#ankara, } \\
\text { @tagesschau, endangerer, } \\
\text { passport, long, terrorist, } \\
\text { crime scene, \#state of war, } \\
\text { trend, Islamist, deport, } \\
\text { Switzerland, @cdu, } \\
\text { perpetrator }\end{array}$ & $\begin{array}{l}\text { The secret truth about the } \\
\text { terrorist attacks } \\
\text { \#BerlinAttacks. }\end{array}$ \\
\hline
\end{tabular}

Table 2. Mapping of topics on Twitter after the Christmas Market attack to typical distal TMT reactions

\subsubsection{Search for meaning and value}

The first topic category derived from our TMT classification scheme focuses on increased sense-making and search for meaning and value. Corresponding tweets with high topic proportions include praying, statements on meaning and sense of the attacks, and content related to religion. The first sub-topic (togetherness) for this category reveals tweets about togetherness such as Berlin mourning together at the Brandenburg Gate or that the Brandenburg Gate will be illuminated in the nation's colors (e.g., "The Brandenburg Gate in \#Berlin will be illuminated tonight in black-red-gold"; "Memorial concert \#BerlinUnited at Brandenburg Gate; \#PrayForBerlin").

The second sub-topic includes statements on meaning and the sense of the attack. For instance, tweets state that Islam is actually a peaceful religion or that people will attend a funeral service. Other statements refer to users' disbelief and sadness over the attacks (e.g., "It hurts so much. These people were looking forward to celebrating Christmas with their families and now they are dead."). However, we also find a small 
number of tweets complaining about how others were using the events to garner personal attention ("I'll do just like everyone else: I'm incredibly sorry, give me likes and attention ... Very sad").

\subsubsection{Nationalistic sentiment, less tolerance, and hostility toward different values and views}

The second topic area includes statements on nationalistic sentiment, less tolerance, and greater hostility toward different values and views. The first sub-topic (xenophobia) comprises tweets on the protection of citizens and closing borders ("What is more important? Open borders for economic reasons or security of citizens? The danger remains"); on internal security and the refugee crisis (e.g., "Alternatives for more security: First, open borders and surveillance inside or second, closed borders and freedom inside. \#BerlinAttack"; "The state has no interest in effectively protecting us from terrorists, so we better get used to \#Breitscheidplatz \& Co."); on world policy, ideology, and trouble spots in Middle East (e.g., "\#BerlinAttack We thank Putin and Assad for destroying the US CIA terrorists for us."); and on radical Islamism and criticism of left-wing parties (e.g., "Left-wingers are right, the danger comes from 'right,' from 'right' religious racist Muslims \#Breitscheidplatz"). There are also some tweets expressing political opinions and thus this topic is related to the topic on calls for political change.

The second sub-topic (political accusation/less tolerance) for this category comprises tweets about laws related to asylum applications. For instance, users blame two political parties—the Green Party (\#Grüne) and the Social Democratic Party (\#SPD)_for blocking strict laws to expel criminal immigrants. We also find sarcastic comments on social and political topics related to secularism (e.g., "\#MerkelChristmas \#cdu \#Grüne \#spd ok! You are right, let's rename Christmas markets to winter markets") and Islamophobia (e.g., “... then cut off their heads" \#Koran \#Merkel \#cdu \#Berlin \#Linke \#Grüne \#Spiegel \#zdf”).

In the third sub-topic, a number of posts call for political change with respect to the refugee crisis in reaction to the terrorist attack. Some users blame the attack, in part, on German Chancellor Angela Merkel and her policy of accepting an unlimited number of asylum seekers and immigrants. Many of them refer to Horst Seehofer, who at the time of the attack was the leader of the Christian Social Union (CSU), a political party in the German state of Bavaria that had openly clashed with Merkel over several issues related to immigration policy ("Dear Horst \#Seehofer, \#Breitscheidplatz and our \#LyingBaron \#Merkel of \#Münchhausen!"; "Dear Horst \#Seehofer, \#Berlin, \#Breitscheidplatz, \#Würzburg, \#Ansbach must have consequences for Angela Merkel!"). Users also reference other terrorist attacks in Germany during 2016. On 18 July, for example, a terrorist attacked passengers on a local train near Würzburg with an axe and knife; and on 24 July, there was a suicide bombing at a music venue in Ansbach.

\subsubsection{Counter-bigotry activism}

In the third topic category on counter-bigotry activism, we find topics that stand in contrast and opposition to those just discussed. The first sub-topic (call for tolerance) reveals tweets in which users take a stand against extremism (e.g., "Let us defend our basic values! For tolerance and openness! Against racism and Islamophobia!"; "Better without Nazis and without Islamists"; \#noNPD \#noAFD") or warn against the possible consequences of fear (e.g., "Fear is the path to the dark side. Fear leads to anger. Anger leads to 
hate. Hate leads to suffering."). Other tweets in this category state that love and Christian values are stronger than hate and violence. This category also includes terms such as "terror," "hate," and "fear," which at first glance may be confusing. However, delving deeper into the tweets made it apparent that users often chose those terms when expressing that the attack and the resulting emotions attack should not lead to nationalism, ostracism, populism, and extremism (e.g., "The answer to the terrorist attacks must be more democracy and more openness. Otherwise the terror has won"; "Hatred, fear and racism are the declared aims of terrorism. Do not let them win").

The second sub-theme (against right-wing propaganda) indicates that some users were worried that the attack would promote right-wing and Euro-skeptic parties: "Sadly, the catastrophe at \#Breitscheidplatz plays into the hands of \#afd \#noAFD \#fckAFD \#noNazis"; "Whatever is pelting down on you now, don't believe the promises and agitations of the right-wing populists!"; "Whoever thinks that voting for \#afd helps against terrorism also thinks that gas helps to extinguish fire"; or "To all Nazis who now say: Foreigners out. I am ashamed of you! \#PrayForBerlin." At the time of our study, the Alternative for Germany (AfD) was an increasingly popular anti-immigrant political party in Germany that had warned that Merkel's "open-door" policy towards refugees had created a security risk. Some tweets call on people from different religions to pray together to point the way against violence (e.g., "\#Church service, Christians, Jews, and Muslims will pray together"). The topic also includes some tweets related to the topic sub-category "community condolences." Finally, a small number of tweets show a certain level of frustration regarding Islamistmotivated terrorist attacks (e.g., "The question is why $1 \%$ of Muslims do this, but not Jews, Christians, Buddhists, atheists").

\subsubsection{Altruistic or pro-social behaviors}

In addition to activism to counter bigotry, users also indicate increased altruistic or pro-social behaviors in tweets in topic category 4. The first sub-topic includes tweets in which users show empathy for people affected directly or indirectly by the terrorist attack and offer sympathy to victims' families (e.g., "Our deepest sympathy and thoughts are with the victims and their relatives \#PrayForTheWorld").

Most of the tweets in the second sub-category (community condolences) are about people from different religions, cities, states, and political organizations showing their sympathy with the victims: "\#Muenster is mourning with \#Berlin"; "\#Lower Saxony mourns with \#Berlin"; "\#National Council of Resistance of Iran mourns for the victims of the attack \#Breitscheidplatz." We also find a small number of sarcastic comments about the terrorist attack in this topic (e.g., "Brother I am here, dead infidels everywhere! I swear!" as a comment on a photograph of a smiling person making a phone call in the background of a live broadcast from Berlin).

\subsubsection{Gratitude for helpers associated with the attacks and hashtag trends}

A small number of tweets express gratitude for the help provided by emergency responders (topic area 5). This topic also covers some tweets from organizations that tried to exploit the trending hashtag 
\#Breitscheidplatz to spread information related to their business interests, such as news about job openings.

\subsubsection{Information seeking and sharing}

The largest category includes ten topics related to information sharing and -seeking. In this topic area, we find, among others, updates on operations from the police, other public authorities, public-service broadcasters (e.g., ARD, ZDF), private news websites (e.g., Spiegelonline, a widely read German-language news website), and television news services (e.g., Tagesschau). The German police used Twitter, for instance, to share and spread a variety of information, such as first informing users that the attack had taken place (Operation update 1), letting users know where they could upload information (Operation update 6), and providing the phone number users should call with tips and questions on the terrorist attacks (Operation update 4). In this category, users also remind others to share only reliable information from official sources, not to speculate, to await the facts (e.g., "What matters: Wait for the investigatory work, do not expect more from the media than they can report and stay alert"), and to criticize how the press and people on the internet are writing about the attack (e.g., "The free-for all competition between @ardhsb @zdf @rtlde is also disgusting").

\subsection{Topic proportions and relations over time}

To answer research question two and thus to examine whether topic proportions were affected by timely patterns over the entire week of observation, we made use of the special feature of our structural topic model: calculating effect estimates to test whether proportions for each topic differed significantly on the day and day after the terrorist attack. Figure 2 includes proportion estimates for the topics "search for meaning and sense" and "xenophobia." We chose these two topics as examples for a topic that predominates the first two days and another one that predominantly occurred on the days that followed. It becomes apparent that content related to search for meaning and sense was more likely to be posted on the day of and day after the attack. That seems plausible given that during those first days people were widely exposed to media coverage about the attack itself, including information about the number of victims and the situation on the ground. In contrast, even though xenophobic content was posted in those same first days, tweets of that sort increased in proportion later in the week.

Appendix B includes figures for the remaining estimates of topic proportions. They indicate that calling for political change and less tolerance were even more common within the next few days, while tweets related to togetherness, calls for tolerance, community condolences, and sympathy and prayers were more likely posted in the first couple of days. Hence, directly after the events, sympathy and the search for meaning are the most common reactions. However, after the initial shock and as more details on the attack became available, such as the perpetrator's background and confirmation that it was definitely a terrorist attack, tweets reflect more xenophobia, nationalism, and less tolerance than in the first two days. This finding is in accordance with prior research indicating that reminders of terrorist attacks produce out-group discrimination (Kaakinen et al., 2018), which in our case is Eurocentrism and xenophobia. 

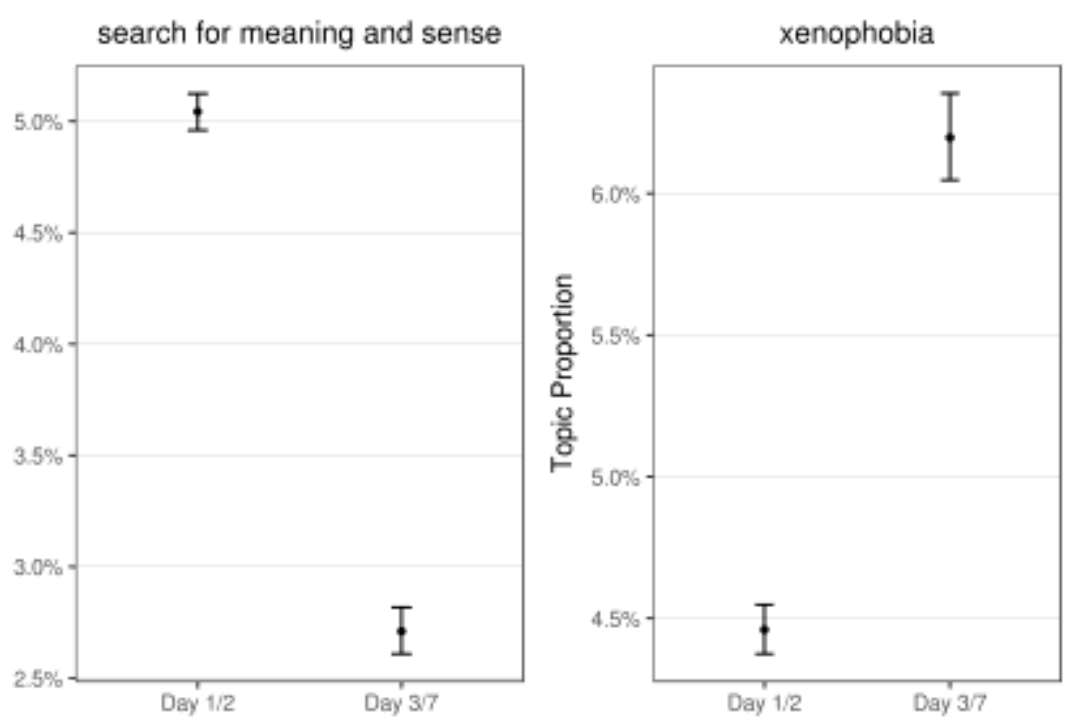

Figure 2. Estimates of topic proportions, based on creation date of tweets. Errors bars denote $95 \%$ confidence intervals.

To examine further the temporal patterns of Twitter reactions in the aftermath of the terrorist attack, we create correlation networks between topics for each time period. The more often topics co-occur in tweets, the higher will be the correlation between those topics. By constructing temporal correlation networks, we can analyze whether the relationship between topics changes in the aftermath of the terrorist attack. In doing so, we calculated the topic correlations separately for tweets of the first two days and tweets posted in the subsequent days, respectively. Next, we created two temporal networks of these correlations in which topics are connected if the pairwise Pearson correlation $R$ between the topic proportions is $\geq 0.05 .{ }^{5}$ All connections extracted this way are significant at $p \geq 0.05$, adjusted with Bonferroni correction for multiple hypothesis tests (Shaffer, 1995). The resulting graphs are visualized in Figure 3 . The strength of an edge in the networks indicates the level of correlation. Regarding the overall structure of both networks, it becomes apparent that for days 3 through 7, topics have more edges. One way to quantify this is by computing the density, which is a ratio of the number of edges to the number of all possible edges in a network. The density for days 1 and 2 has a value of 0.12 , whereas the density for days 3 through 7 is comparatively higher with a value of 0.26 . One reason for this difference might be that directly after the attack many different details about the event were published and different topics arose, whereas in the subsequent days words and opinions aligned with most of the published content (Chun \& Lee, 2017).

Despite the difference in network densities, some connections between topics are rather stable over time. Topics about "operation updates" are related in both networks, because the police and media constantly updated information regarding the attack and, in doing so, the tweets often referred to each other. Both

${ }^{5}$ Correlation matrices for constructing the topic networks are available upon request. 
networks include clusters between the political topics about "xenophobia," "call for political change," and "against right-wing propaganda." Furthermore, due to their content-related similarity it makes sense to find relationships in both networks between the two topics "community condolences" and "togetherness." Likewise, we find a relation between the two topics "sympathy and prayers" and "search for meaning and sense" in both networks. With respect to isolated topics with no substantial correlations, only minor differences are apparent. In both time periods, for instance, "gratitude for helpers" and "terror info/hashtags" are isolated, indicating that corresponding tweets do not, for the most part, contain content of any other topics.

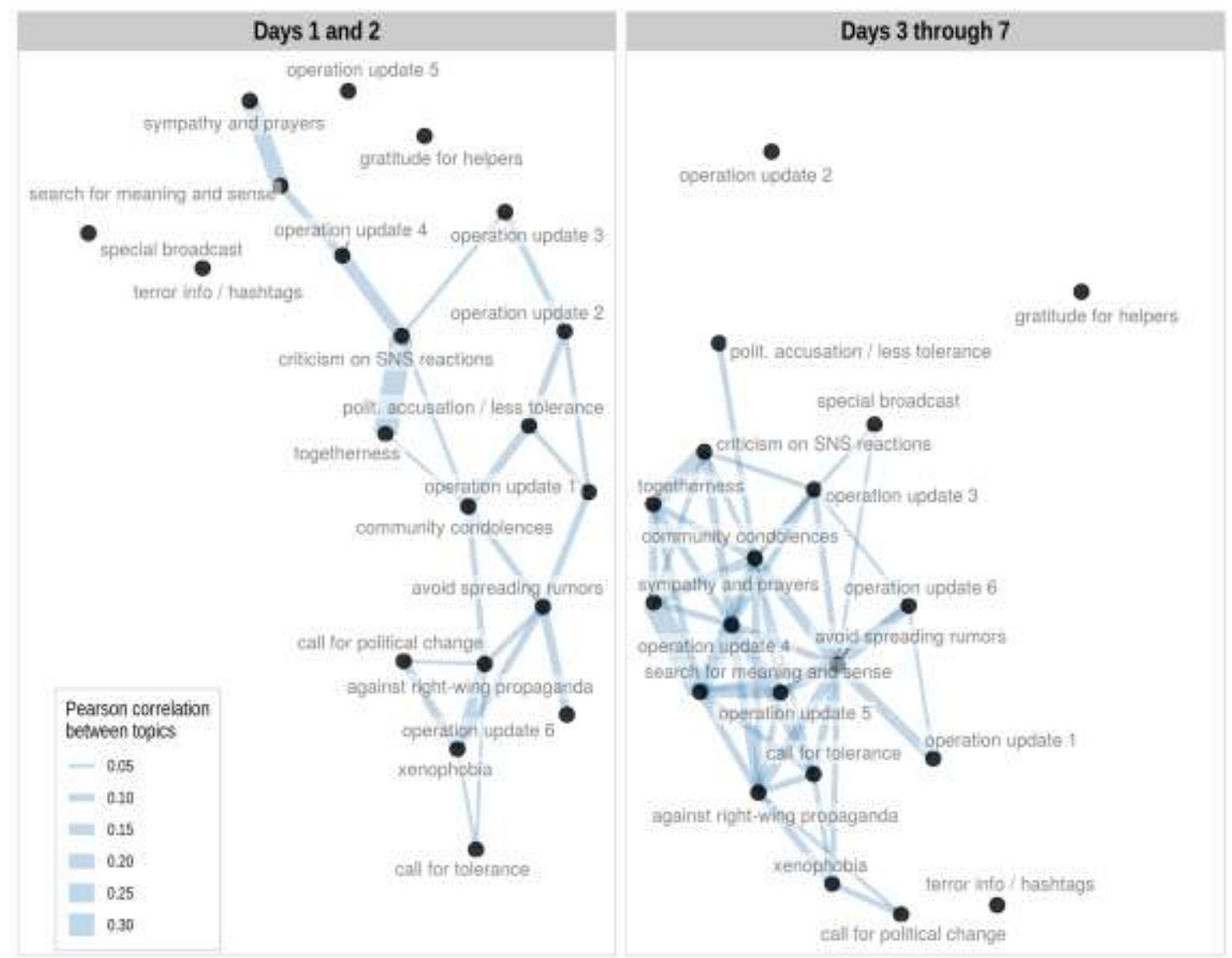

Figure 3. Correlation network of the structural topic model. Edges indicate the correlation between topics.

In summary, our analyses of temporal patterns reveal substantial differences in the appearance of topics over time. Initial tweets were more emotional, expressing empathy for the victims and their families, condolences, awareness, grief, a search for the reasons of the attack, and calls for peace and against exclusion and violence. Tweets in the subsequent days included more content about xenophobia, 
nationalism, and less tolerance than what was posted during the first two days. In addition, relationships between the topics are denser in the subsequent days after the terrorist attack.

\section{Discussion}

\subsection{Theoretical discussion}

Our paper's purpose is to identify common terror management reactions and their timely patterns on Twitter, at the collective level, in the aftermath of the 2016 Berlin Christmas market terrorist attack. By complementing sense-making with TMT, we explain why it is so important for people to seek and share information, and verify feelings, behavior, and opinions. We used this perspective as a theoretical lens to analyze the topics that occurred in the aftermath of the attack. In doing so, we answered our first research question and identified togetherness, the search for meaning and sense, xenophobia, less tolerance, calls for political change, calls for tolerance, a stand against right-wing propaganda, sympathy and prayers, community condolences, gratitude for helpers, the avoidance of spreading rumors, criticism of reporting, and operational updates as topics particularly relevant for Twitter users. From a TMT perspective these reactions indicate that some Twitter users seemed to reestablish their worldview and self-esteem collectively by connecting with others and sharing opinions, sympathy, and information. Additionally, these reactions serve as anxiety-buffering, worldview-defense, and self-esteem-bolstering functions of terror management strategies (Pyszczynski et al., 2003; Yum \& Schenck-Hamlin, 2005).

Our results suggest further that SNS help complement the specific communication needs people have in the days after a terrorist attack and that this is also effected by timely patterns (see research question two). Information sharing through Twitter, as well as pro-social behavior such as the search for meaning and sense, sympathy and prayers, togetherness, and calls for tolerance dominated the first two days of the terrorist attack and are typical sense-making and TMT reactions. Some of the tweets in the "search for meaning and sense" category, for instance, indicate shock and disbelief ("Incredibly sad. I can hardly believe it!"), which are typical initial reactions to death-reminders in TMT. Likewise, tweets in this category indicate that people, cities, and nations will pray and mourn together and express condolences, which is a common distal reaction to death-reminders to reestablish sense and meaning and reduce anxiety (Pyszczynski et al., 2003) and cope with the events (e.g., Eriksson, 2015; Neubaum et al., 2014; Nilsen et al., 2018).

In addition, sharing emotions to support or help each other has proven to be an important part of SNS use after both natural and human-made disasters. Hence, in line with prior research, we find that the immediate response (days 1 and 2) is imprinted with pro-social behavior and by the need to find and share information regarding the situation (e.g., Heverin \& Zach, 2012; Neubaum et al., 2014; Nilsen et al., 2018). Twitter offered a public space for expressing and sharing grief and support and making sense of the traumatic events. 
Furthermore, around $50 \%$ of tweet content belongs to the category "information seeking and sharing." In accordance with the sense-making and TMT perspectives, Twitter users gathered and shared pieces of missing information to acquire understanding (e.g., Heverin \& Zach, 2012; Palen et al., 2009; Stieglitz et al., 2018). In particular, at the beginning of a crisis, people try to learn what is happening and, particularly during terrorist attacks, sense-making can be very difficult because of the moving, adaptive, and intelligent opponent (the terrorist). These complex situations often create a lack of information, hamper understanding of the event, and thus create high levels of anxiety (Bux \& Coyne, 2009). In the Berlin case, it was not clear at first whether it was a terrorist attack or an accident. Hence, users began to speculate about the motive of the perpetrator, which was then criticized in several tweets. In response, private Twitter users, as well as the police and media outlets, constantly updated information on the operation and also pointed out that speculation and rumors had to be avoided.

However, after the first two days, when the perpetrator's motive became clear and the first shock was over, we find fewer emotion-related and more opinion-related tweets in the topic proportions. In line with evidence from TMT research, tweets indicate a tendency to support those who share one's political orientation (\#afd, \#noNazis) or religion (\#MuslimsAgainstTerror), while rejecting people with different views (e.g., Greenberg \& Arndt, 2012). By assigning specific hashtags to their tweets, people began to use Twitter to foster public awareness of political, social, or cultural issues in reaction to the events, as several topics in our dataset indicate. For instance, some users blamed German Chancellor Angela Merkel (\#MerkelChristmas) for the attack because of her refugee asylum policy. This finding is also in accordance with prior research on different affordances of SNS that claims that SNS allow users to find or group with likeminded others without any regional boundaries and then share their opinions (Williams \& Burnap, 2016).

Likewise, we found topics on xenophobic, Islamophobic, anti-immigration, and nationalistic statements, which is in line with evidence from TMT research arguing that hostility toward a perceived enemy increases when people have been confronted with death (e.g., Cohen et al., 2005), and also with findings about online hate indicating that in the aftermath of terrorist attacks there is an increase on SNS platforms of hate speech against people with characteristics similar to those of the terrorist perpetrator (Kaakinen et al., 2018; Williams \& Burnap, 2016). We found further that forces from across the political spectrum-such as Euroskeptic, left-wing, and right-wing parties-also use the attention such attacks garner on Twitter to promote their agendas. Moreover, our case study reveals that some users took a stand against right-wing populism, xenophobia, and ostracism, took a liberal stance to the refugee crisis, or called for tolerance in reaction to the terrorist attacks. This reasoning is consistent with the TMT explanation that people argue in accord with their worldview to conform to their cultural values and maintain their sense of self-esteem and worth (Yum \& Schenck-Hamlin, 2005). Hence, there is not only hateful speech on SNS but also tweets taking a stance against hostile reactions.

In line with prior research, the topics changed over time in the aftermath of the terrorist attacks (Eriksson, 2015; Olteanu et al., 2015; Vieweg et al., 2010). Although we found many general similarities with other 
crisis events in terms of the topics that predominate the time directly after a crisis event, such as many situation-related tweets (e.g., operational updates; avoid spreading rumors) and emotion-related topics (e.g., togetherness; sympathy and prayers) in the direct aftermath of the crisis event, our analysis of topic content and time patterns reveals that topics occur to different degrees and sometimes with different purposes depending on the type of crisis event, the context in which it takes place, and the course of the event. For instance, in the subsequent days, we found a higher proportion of opinion-related topics closely related to the social debates and political situation that took place in Germany, such as the refugee crisis.

We concluded that Twitter serves to facilitate finding and sharing information, validating and living up to the standards one associates with one's worldview, and reestablishing self-esteem. Terrorist attacks in particular trigger worldview defense and maintenance of one's self-esteem because they can be seen as death-reminders and an attack against worldviews that embrace democracy and basic Western values. Twitter users argue their worldviews, discuss and validate their opinions, and express personal views, all of which are important for coping with terrorist attacks and reducing anxiety. By connecting people and providing a real-time communication channel, Twitter helps users collectively live up to the standards they associate with their worldviews and helps them determine whether other users have a similar perspective on a given issue.

\subsection{Implications for policy-makers}

Our research contributes to understanding individuals' decisions to interact on SNS when exogenous shocks occur. In particular, during a terrorist attack and its aftermath, we find the underlying motives (worldview defense, self-esteem striving) influence the content people share online (e.g., condolences, xenophobic content, calls for political change). In times of terrorist attacks, managers of SNS must monitor their platforms closely for hate speech or inciteful comments, while at the same time ensuring that their platforms can continue to be useful in helping people reduce their anxiety and cope with events at a collective level. Hence, on the one hand, managers of SNS platforms and policymakers should develop response strategies to reply to hate speech in the aftermath of terrorist attacks. On the other hand, managers of SNS platforms should continue to provide tools that enable people to show sympathy or help people make sense after such events. For instance, a tool that allows users to indicate on their profile that they are safe (e.g., Safety Check on Facebook) or an option to include in the profile picture an overlay of the flag of a country in which a terrorist attack has occurred. However, managers of SNS platforms should be aware that these tools may also increase uncertainty or be used to express intolerance or to foster an inter-group conflict. Thus, they should carefully consider and monitor these tools.

\section{Limitations and future research}

Our study is not without limitations. Our data, and therefore our results, depend on the hashtags we used to identify tweets related to the attack. Although we monitored the platform extensively for all relevant hashtags, it is possible that we missed some related to the terrorist attack. In addition, although event- 
related hashtags are very common on Twitter, some users probably tweeted about the attacks without using any hashtags, and hence we did not capture their tweets in our dataset. Furthermore, there is evidence from prior research on human-made crises that people also use SNS platforms passively, for instance only by consuming content produced by other SNS users to comprehend crisis events (Neubaum et al., 2014). Future research could investigate SNS usage at the individual level from the TMT and sense-making perspectives to understand this passive use of SNS after terrorist attacks.

Moreover, we investigated a terrorist attack that took place in Germany. Although the general course of topics-from tweets that are more information-related and emotional in the beginning to more opinionrelated in the subsequent days -is similar to other human-made crises outside Germany (Eriksson, 2015; Heverin \& Zach, 2012), we believe people in countries with different cultural, economic, and political context factors might process or perceive terrorist attacks differently. Future research could investigate SNS usage in the wake of terrorist attacks in countries other than Germany, and investigate how topics vary.

Furthermore, future research could compare the responses of users of different SNS. Different features of SNS platforms may influence the responses in the aftermath of a terrorist attack. For instance, Facebook does not restrict the length of posts, and enables users to establish groups on a certain subject/common goal. Further research could explore how platform-specific features and affordances might influence people's online behavior in the wake of terrorist attacks (e.g., the creation of crisis-specific groups on Facebook).

Although after terrorist attacks people have a need to exchange information about the event, prior research indicates that the perceived (personal) relevance of a crisis event influences the use of SNS in the aftermath of a terrorist attack (Neubaum et al., 2014; Nilsen et al., 2018; Takahashi et al., 2015). Of course, Germans perceive the terrorist attack in Berlin differently than people from culturally different or geographically distant countries. Future research could compare the reactions on SNS in the aftermath of a terrorist attack from the TMT perspective in terms of these cultural and geographic differences and distances.

\section{Conclusion}

Using the sense-making and TMT perspectives, we provide an explanation of the emergence of psychological needs in the aftermath of terrorist attacks and identify common terror management reactions on Twitter in the aftermath of the 2016 Berlin Christmas market terrorist attack. In particular, we find that Twitter served as a facilitator for finding and sharing information, validating and living up to the standards one associates with one's worldview, reestablishing self-esteem, and making sense of the events. Thus, our study contributes to the understanding of people's collective usage behavior of Twitter in the aftermath of terrorist attacks. 


\section{References}

Baez, S., Herrera, E., García, A. M., Manes, F., Young, L., \& Ibáñez, A. (2017). Outcome-oriented moral evaluation in terrorists. Nature Human Behaviour, 1, 118.

Benoit, K., Watanabe, K., Wang, H., Nulty, P., Obeng, A., Müller, S., \& Matsuo, A. (2018). Quanteda: An R package for the quantitative analysis of textual data. Journal of Open Source Software, 3, 774.

Blei, D. M. (2012). Probabilistic topic models. Communications of the ACM, 55, 77.

Burke, B. L., Martens, A., \& Faucher, E. H. (2010). Two decades of terror management theory: A meta-analysis of mortality salience research. Personality and Social Psychology Review: an Official Journal of the Society for Personality and Social Psychology, 14, 155-195.

Bux, S. M., \& Coyne, S. M. (2009). The effects of terrorism: The aftermath of the London terror attacks. Journal of Applied Social Psychology, 39, 2936-2966.

Chang, J., Boyd-Graber, J., Gerrish, S., Wang, C., \& Blei, D. (2009). Reading tea leaves: How humans interpret topic models. In Proceedings of the Advances in Neural Information Processing Systems (pp. 1-9).

Chun, J. W., \& Lee, M. J. (2017). When does individuals' willingness to speak out increase on social media? Perceived social support and perceived power/control. Computers in Human Behavior, 74, 120-129. https://doi.org/10.1016/j.chb.2017.04.010

Cohen, F., Ogilvie, M., Solomon, S., Greenberg, J., \& Pyszczynski, T. (2005). American roulette: The effect of reminders of death on support for George W. Bush in the 2004 presidential election. Analyses of Social Issues and Public Policy, 5.

Cohen, K., Johansson, F., Kaati, L., \& Mork, J. C. (2013). Detecting linguistic markers for radical violence in social media. Terrorism and Political Violence, 26, 246-256.

Cornelissen, J. P., Mantere, S., \& Vaara, E. (2014). The Contraction of Meaning: The Combined Effect of Communication, Emotions, and Materiality on Sensemaking in the Stockwell Shooting. Journal of Management Studies, 51, 699-736. https://doi.org/10.1111/joms.12073

Crenshaw, M. (2000). The psychology of terrorism: An agenda for the 21st century. Political Psychology, 21, 405420.

Das, E., Bushman, B. J., Bezemer, M. D., Kerkhof, P., \& Vermeulen, I. E. (2009). How terrorism news reports increase prejudice against outgroups: A terror management account. Journal of Experimental Social Psychology, 45, 453-459.

Debortoli, S., Müller, O., Junglas, I., \& Vom Brocke, J. (2016). Text mining for information systems researchers: An annotated topic modeling tutorial. Communications of the Associations for Information Systems, 39, 110-135.

Dpa. (2017). Background. Retrieved from https://www.nexis.com/results/enhdocview.do?docLinkInd=true\&ersKey=23_T26851646190\&format=GNBFI\&start DocNo $=251$ \&resultsUrlKey $=0 \_$T26851892369\&backKey $=20 \_T 26851892370$ \&csi $=144245 \&$ docNo $=257$

Dunkel, C. S. (2002). Terror management theory and identity: The effect of the $9 / 11$ terrorist attacks on anxiety and identity change. Identity, 2, 287-301.

EENA. (2016). EENA Case Study. Brussels Attacks. Crossover between research and reality. Retrieved from https://eena.org/wp-content/uploads/2018/11/Brussels-Attacks-Case-Study.pdf

Eriksson, M. (2015). Managing collective trauma on social media: The role of Twitter after the 2011 Norway attacks. Media, Culture \& Society, 38, 365-380.

Fischer, D., Eismann, K., \& Fischbach, K. (2016). Usage behavior of social network sites in the aftermath of terrorist attacks. In International Conference on Information Systems.

Frees, B., \& Koch, W. (2018). ARD/ZDF-Onlinestudie: Zuwachs bei medialer Internetnutzung und Kommunikation. ARD/ZDF-Onlinestudie 2018. Retrieved from http://www.ard-zdf-onlinestudie.de/files/2018/0918_Frees_Koch.pdf

Greenberg, J., \& Arndt, J. (2012). Terror management theory. In A. W. van Lange, A. W. Kruglanski, \& E. T. Higgins (Eds.), Handbook of Theories of Social Psychology (pp. 398-415). London: Sage Publications.

Greenberg, J., Arndt, J., Pyszczynski, T., \& Solomon, S. (2000). Proximal and distal defenses in response to reminders of one's mortality: Evidence of a temporal sequence. Personality and Social Psychology Bulletin, 26, 91-99.

Greenberg, J., Pyszczynski, T., \& Salomon, S. (1986). The causes and consequences of the need for self-esteem: A terror management theory. In Public Self and Private Self 1986 (pp. 189-212).

Grimmer, J., \& Stewart, B. M. (2013). Text as data: The promise and pitfalls of automatic content analysis methods for political texts. Political Analysis, 21, 267-297.

Haugerud, A. (2016). Public Anthropology in 2015: Charlie Hebdo Black Lives Matter, Migrants, and More. American Anthropologist, 118, 585-601. https://doi.org/10.1111/aman.12606 
Heverin, T., \& Zach, L. (2012). Use of microblogging for collective sense-making during violent crises: A study of three campus shootings. Journal of the American Society for Information Science and Technology, 63, 34-47.

Holmes, S. M., \& Castaneda, H. (2016). Representing the "European refugee crisis" in Germany and beyond: Deservingness and difference, life and death. American Ethnologist, 43, 12-24. https://doi.org/10.1111/amet.12259

Huberman, B., Romero, D. M., \& Wu, F. (2009). Social networks that matter: Twitter under the microscope. First Monday, 14.

Jonas, E., Schimel, J., Greenberg, J., \& Pyszczynski, T. (2016). The Scrooge effect: Evidence that mortality salience increases prosocial attitudes and behavior. Personality and Social Psychology Bulletin, 28, 1342-1353.

Jong, W., \& Dückers, M. L.A. (2016). Self-correcting mechanisms and echo-effects in social media: An analysis of the "gunman in the newsroom" crisis. Computers in Human Behavior, 59, 334-341. https://doi.org/10.1016/j.chb.2016.02.032

Kaakinen, M., Oksanen, A., \& Räsänen, P. (2018). Did the risk of exposure to online hate increase after the November 2015 Paris attacks? A group relations approach. Computers in Human Behavior, 78, 90-97. https://doi.org/10.1016/j.chb.2017.09.022

Kaewkitipong, L., Chen, C. C., \& Ractham, P. (2016). A community-based approach to sharing knowledge before, during, and after crisis events: A case study from Thailand. Computers in Human Behavior, 54, 653-666. https://doi.org/10.1016/j.chb.2015.07.063

Kane, G. C., Alavi, M., Labianca, \& Borgatti, S. P. (2014). What's different about social media networks? A framework and research agenda. MIS Quarterly, 38, 274-304.

Kaufhold, M.-A., \& Reuter, C. (2016). The self-organization of digital volunteers across social media: The case of the 2013 European floods in Germany. Journal of Homeland Security and Emergency Management, $13,679$. https://doi.org/10.1515/jhsem-2015-0063

Kiwan, N. (2016). Freedom of thought in the aftermath of the Charlie Hebdo attacks. French Cultural Studies, 27, 233-244.

Kruglanski, A. W., Bélanger, J. J., Gelfand, M., Gunaratna, R., Hettiarachchi, M., Reinares, F., ... Sharvit, K. (2013). Terrorism--A (self) love story: redirecting the significance quest can end violence. The American Psychologist, 68, $559-575$.

Lachlan, K. A., Spence, P. R., \& Seeger, M. (2009). Terrorist attacks and uncertainty reduction: Media use after September 11. Behavioral Sciences of Terrorism and Political Aggression, 1, 101-110.

Landau, M. J., Solomon, S., Greenberg, J., Cohen, F., Pyszczynski, T., Arndt, J., . . Cook, A. (2004). Deliver us from evil: The effects of mortality salience and reminders of $9 / 11$ on support for president George W. Bush. Personality and Social Psychology Bulletin, 30, 1136-1150.

Lerner, J. S., Gonzalez, R. M., Small, D. A., \& Fischhoff, B. (2003). Effects of fear and anger on perceived risks of terrorism: A national field experiment. Psychological Science, 14, 144-150.

Lucas, C., Nielsen, R. A., Roberts, M. E., Stewart, B. M., Storer, A., \& Tingley, D. (2015). Computer-assisted text analysis for comparative politics. Political Analysis, 23, 254-277.

Maitlis, S., \& Christianson, M. (2014). Sensemaking in organizations: Taking stock and moving forward. The Academy of Management Annals, 8, 57-125.

McGregor, H. A., Liebermann, J. D., Greenberg, J., Solomon, S., Arndt, J., Simon, L., \& Pyszczynski, T. (1998). Terror management and aggression: Evidence that mortality salience motivates aggression against worldviewthreatening others. Journal of Personality and Social Psychology, 74, 590-605.

Mendoza, M., Poblete, B., \& Castillo, C. (2010). Twitter under crisis: Can we trust what we rt? In 1st Workshop on Social Media Analytics.

Mimno, D., Wallach, H. M., Talley, E., Leenders, M., \& McCallum, A. (2011). Optimizing semantic coherence in topic models. In Proceedings of the Conference on Empirical Methods in Natural Language Processing (pp. 262-272).

Morstatter, F., Pfeffer, J., Liu, H., \& Carley, K. M. (2013). Is the sample good enough? Comparing data from Twitter's streaming API with Twitter's firehose. In Proceedings of the 7th International Conference on Weblogs and Social Media (pp. 400-408).

Neubaum, G., Rösner, L., Rosenthal-von der Pütten, A. M., \& Krämer, N. C. (2014). Psychosocial functions of social media usage in a disaster situation: A multi-methodological approach. Computers in Human Behavior, 34, 28-38. https://doi.org/10.1016/j.chb.2014.01.021

Nilsen, L. G., Hafstad, G. S., Staksrud, E., \& Dyb, G. (2018). Five reasons for using social media among young terror survivors: Results from the Utøya study. Computers in Human Behavior, 84, 285-294. https://doi.org/10.1016/j.chb.2018.03.006

Oh, O., Chanyoung, E., \& Rao, H. R. (2012). Collective sense-making through Twitter service during the 2011 Egypt 
revolution. In International Conference on Information Systems 2012 (pp. 1-10).

Oh, O., Eom, C., \& Rao, H. R. (2015). Research note -Role of social media in social change: An analysis of collective sense making during the 2011 Egypt revolution. Information Systems Research, 26, 210-223.

Olteanu, A., Vieweg, S., \& Castillo, C. (2015). What to expect when the unexpected happens: Social media communications across crises. In D. Cosley, A. Forte, L. Ciolfi, \& D. McDonald (Eds.), Proceedings of the 18th ACM Conference on Computer Supported Cooperative Work \& Social Computing - CSCW '15 (pp. 994-1009). New York, New York, USA: ACM Press. https://doi.org/10.1145/2675133.2675242

Palen, L., Vieweg, S., Liu, S. B., \& Hughes, A. L. (2009). Crisis in a networked world. Social Science Computer Review, 27, 467-480.

Pang, N., \& Ng, J. (2016). Twittering the Little India Riot: Audience responses, information behavior and the use of emotive cues. Computers in Human Behavior, 54, 607-619. https://doi.org/10.1016/j.chb.2015.08.047

Pedersen, T. L. (2018). Ggraph: An Implementation of Grammar of Graphics for Graphs and Networks. R package version 1.0.1. Retrieved from https://CRAN.R-project.org/package=ggraph

Pyszczynski, T. (2004). What are we so afraid of? A terror management theory perspective on the politics of fear. Social Research, 71, 827-848.

Pyszczynski, T., Greenberg, J., \& Solomon, S. (1999). A dual-process model of defense against conscious and unconscious death-related thoughts: An extension of terror management theory. Psychological Review, 106, 835845.

Pyszczynski, T., Solomon, S., \& Greenberg, J. (2003). In the wake of 9/11: The psychology of terror. Washington, DC: American Psychological Association.

Roberts, M. E., Stewart, B. M., Tingley, D., Lucas, C., Leder-Luis, J., \& Rand, D. G. (2014). Structural topic models for open-ended survey responses. American Journal of Political Science, 58, 1064-1082.

Rogers, R. B., Amlôt, R., Rubin, G. J., Wessely, S., \& Krieger, K. (2007). Mediating the social and psychological impacts of terrorist attacks: The role of risk perception and risk communication. International Review of Psychiatry, 19, 279-288.

Schimel, J., Simon, L., Greenberg, J., Pyszczynski, T., Solomon, S., Waxmonsky, J., \& Arndt, J. (1999). Stereotypes and terror management: Evidence that mortality salience enhances stereotypic thinking and preferences. Journal of Personality and Social Psychology, 77, 5-926.

Shaffer, J. P. (1995). Multiple hypothesis testing. Annal Review of Psychology, 46, 561-584.

Simon, T., Goldberg, A., \& Adini, B. (2015). Socializing in emergencies-A review of the use of social media in emergency situations. International Journal of Information Management, 35, 609-619.

Stieglitz, S., Bunker, D., Mirbabaie, M., \& Ehnis, C. (2018). Sense-making in social media during extreme events. Journal of Contingencies and Crisis Management, 26, 4-15.

Sutton, J., Spiro, E. S., Fitzhugh, S., Johnson, B., Gibson, B., \& Butts, C. T. (2014). Terse message amplification in the Boston bombing response. In Proceedings of the 11th International ISCRAM Conference (pp. 612-621).

Takahashi, B., Tandoc, E. C., \& Carmichael, C. (2015). Communicating on Twitter during a disaster: An analysis of tweets during Typhoon Haiyan in the Philippines. Computers in Human Behavior, 50, 392-398. https://doi.org/10.1016/j.chb.2015.04.020

Vieweg, S., Hughes, A. L., Starbird, K., \& Palen, L. (2010). Microblogging during two natural hazards events: What Twitter may contribute to situational awareness. In CHI 2010: Crisis Informatics (pp. 1079-1088). Atlanta, GA, USA.

Wallach, H. M., Salakhutdinov, I. M. R., \& Mimmo, D. (2009). Evaluation methods for topic models. In International Conference on Machine Learning.

Weick, K. E. (1988). Enacted sensemaking in crisis situations. Journal of Management Studies, 25, 305-317.

Weick, K. E. (1995). Sensemaking in organizations. Thousand Oaks, London, New Delhi: Sage Publications.

Weise, D. R., Pyszczynski, T., Cox, C. R., Arndt, J., Greenberg, J., Solomon, S., \& Kosloff, S. (2007). Interpersonal politics-The role of terror management and attachment processes in shaping political preferences. Psychological Science, 19, 448-455.

Wickham, H. (2017). Tidyverse: Easily Install and Load the 'Tidyverse'. R package version 1.2.1. Retrieved from https://CRAN.R-project.org/package=tidyverse

Williams, M. L., \& Burnap, P. (2016). Cyberhate on Social Media in the aftermath of Woolwich: A Case Study in Computational Criminology and Big Data. British Journal of Criminology, 56, 211-238. https://doi.org/10.1093/bjc/azv059

Yum, Y., \& Schenck-Hamlin, W. (2005). Reactions to 9/11 as a function of terror management and perspective taking. The Journal of Social Psychology, 145, 265-286. 
Zaleskiewicz, T., Gasiorowska, A., \& Kesebir, P. (2015). The Scrooge effect revisited: Mortality salience increases the satisfaction derived from prosocial behavior. Journal of Experimental Social Psychology, 59, 67-76.

\section{APPENDIX A}

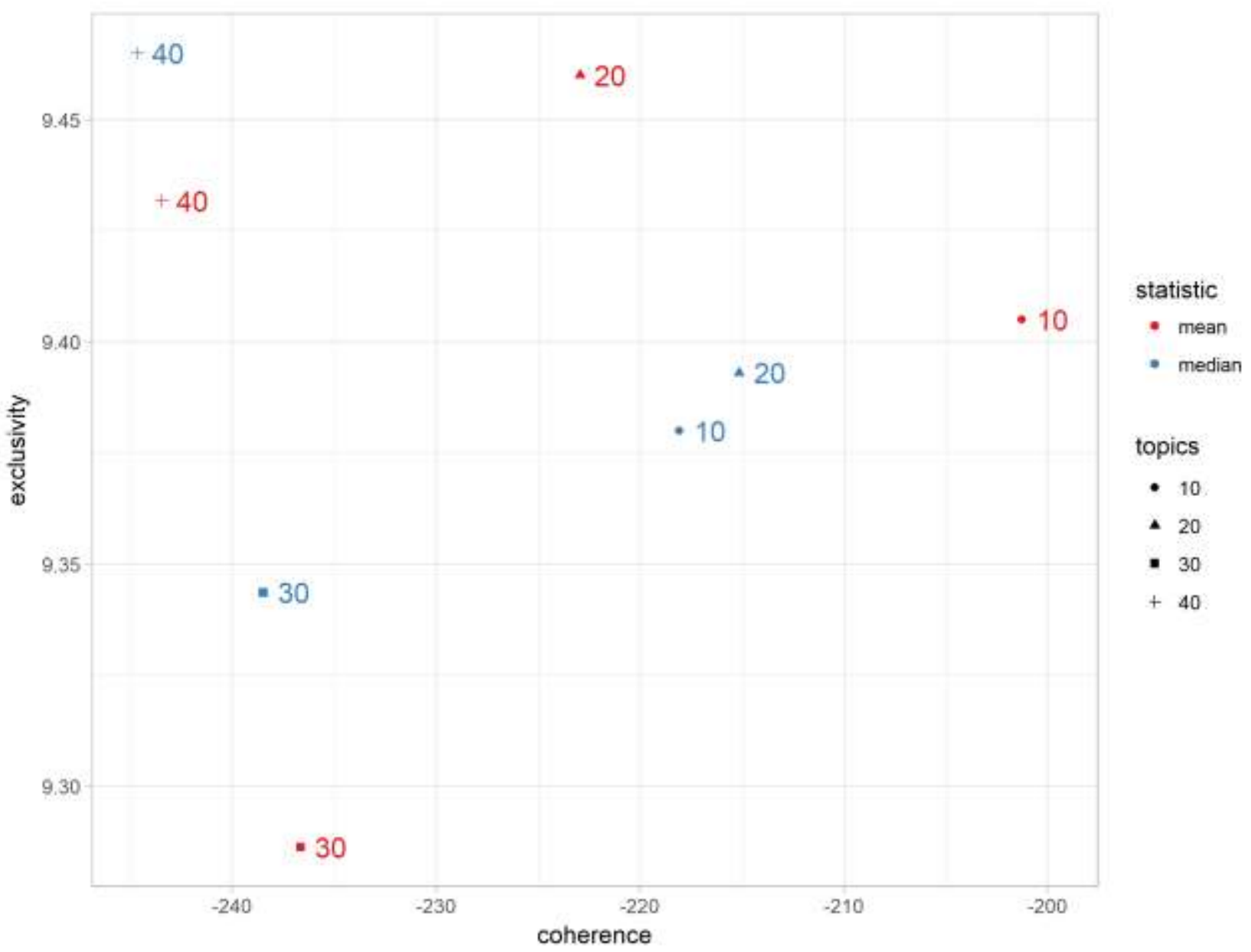

Figure A1. Model diagnostics for structural topic models. Mean and median statistics are computed over all topics of the corresponding model. 


\section{APPENDIX B}

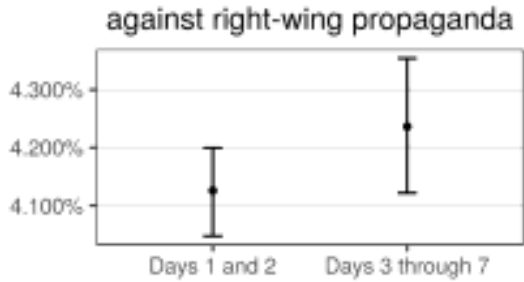

togetherness

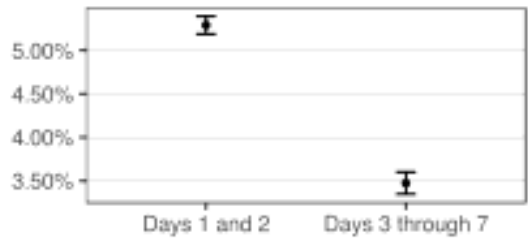

community condolences

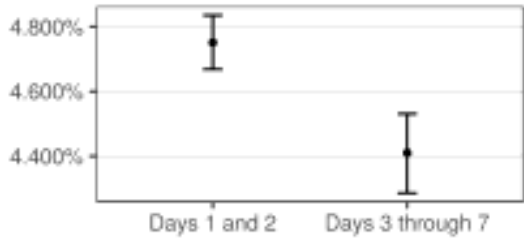

operation update 2

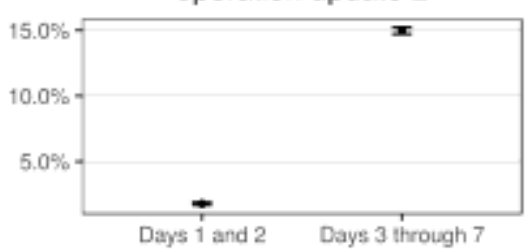

operation update 5

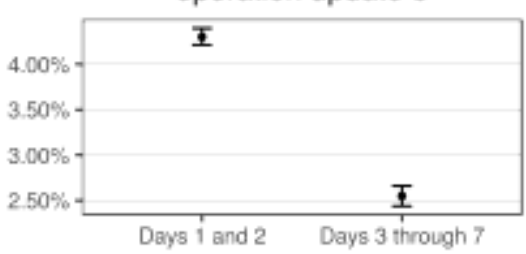

avoid spreading rumors

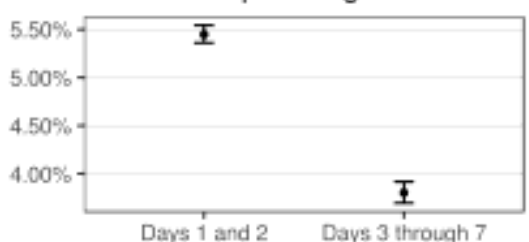

polit. accusation / less tolerance

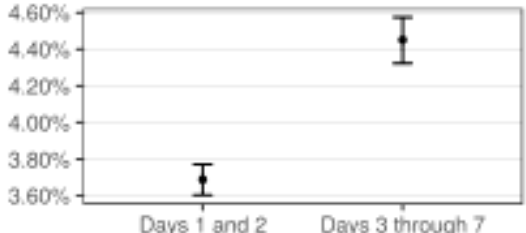

call for tolerance

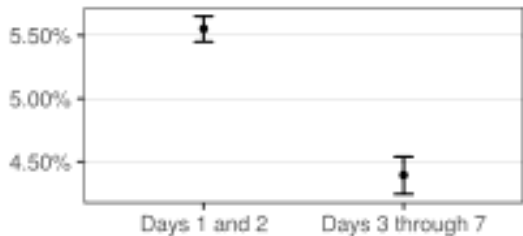

gratitude for helpers

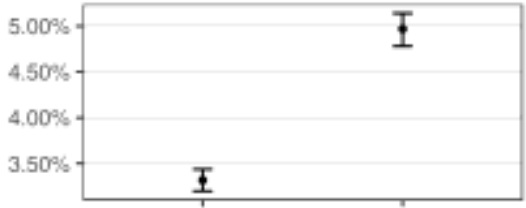

Days 1 and 2 Days 3 through 7

operation update 3

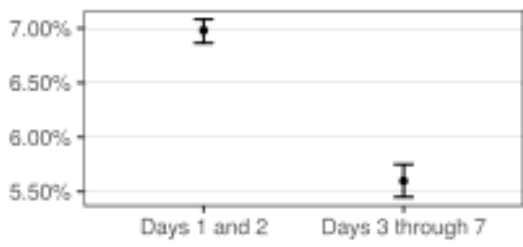

operation update 6

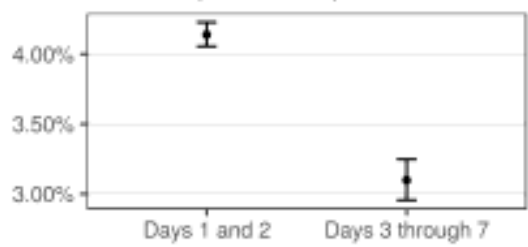

criticism on SNS reactions

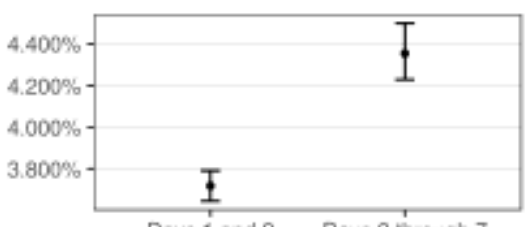

Days 1 and 2 Days 3 through 7

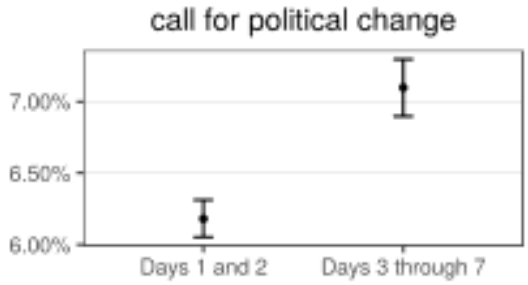

sympathy and prayers

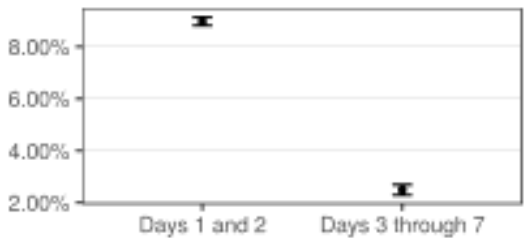

operation update 1

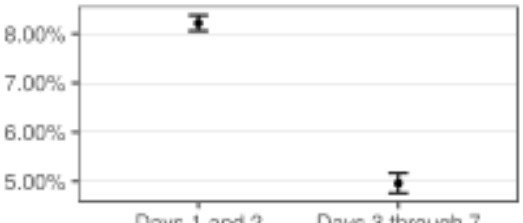

operation update 4

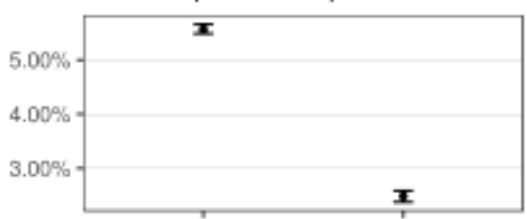

Days 1 and 2 Days 3 through 7

special broadcast

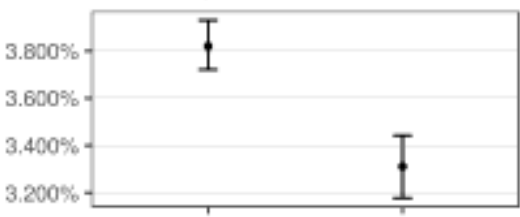

Days 1 and 2 Days 3 through 7 terror info / hashtags

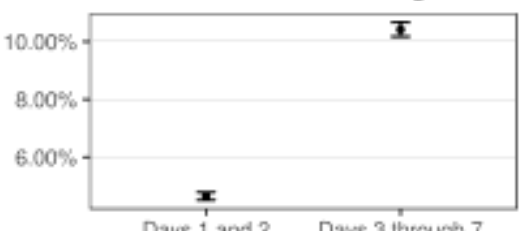

Figure B1. Estimates of topic proportions dependent on creation date of tweets in the December week of the Berlin terrorist attack. Error bars represent 95\% confidence intervals. 